JOURNAL OF LAW, TECHNOLOGY \& THE INTERNET • VOL. 12 • NO. 5 • 2020-2021

\title{
QUANTUM MACHINE LEARNING: A PATENT REVIEW
}

\author{
Brian S. Haney*
}

One of the central problems bottlenecking machine learning research is classical computational power limits. Quantum computing provides a solution, offering more processing power for less electric cost. Quantum Machine Learning (QML) is a research field at the intersection of quantum computing and machine learning technologies, driving the cutting edge in technological innovation. While the legal literature on software patents is rapidly scaling, the research focused on QML patents is noticeably nascent. As such, this Article contributes the first empirical patent survey for QML technologies

\footnotetext{
* Brian S. Haney Copyright 2020. Thanks to Angela Elias, Hon. Clarence Thomas, Hon. Richard Posner, Geoff Hinton, Samantha Zyontz, Stefania Fusco, Branden Keck, Broderick Haney, Brad Haney, Dave Elias, Leslie Kaelbling, Elona Marku, Colleen Chien, Amir Kaley, Joel Gottlieb, Mikel Kota, and Jeanne Fromer for the helpful suggestions, comments, ideas, and encouragement.
} 


\section{CONTENTS}

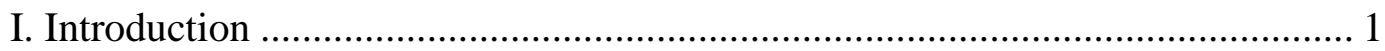

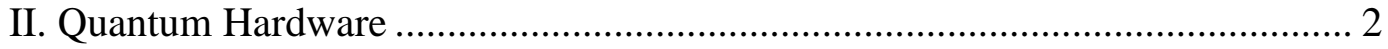

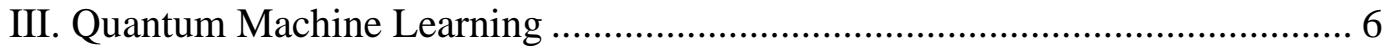

A. Predictive Graphing .................................................................. 7

1. Quantum Neural Networks ........................................................... 7

2. Quantum Boltzmann Machines ....................................................... 10

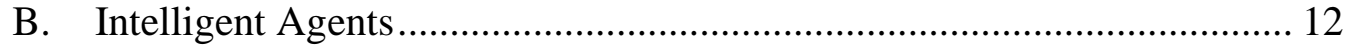

1. Reinforcement Learning .......................................................... 12

2. Quantum Markov Models ............................................................ 13

C. Quantum Convergence....................................................................... 14

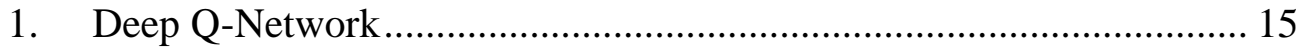

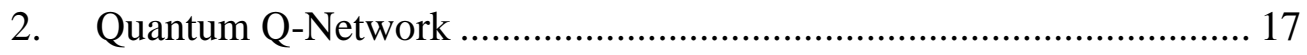

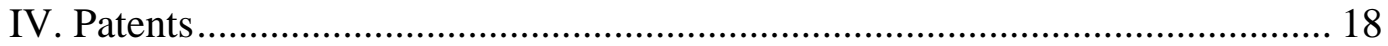

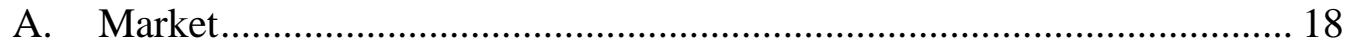

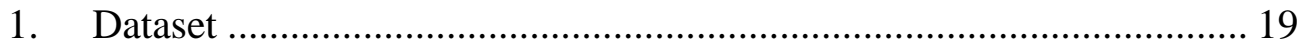

2. Growth Trajectory ................................................................... 20

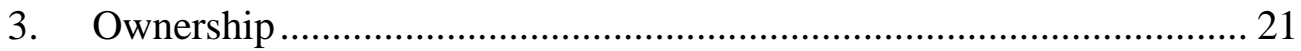

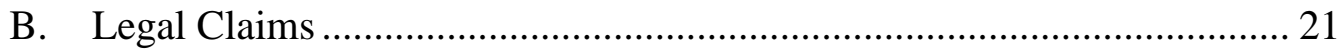

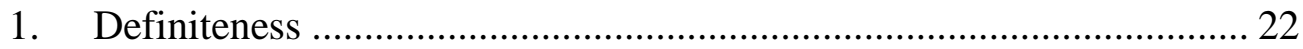

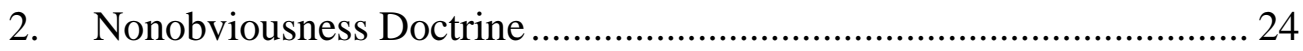

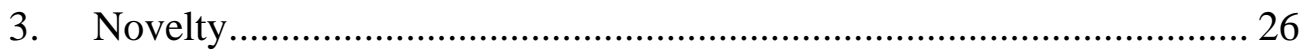

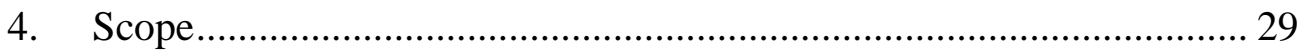

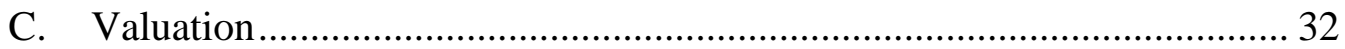

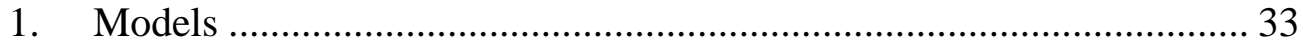

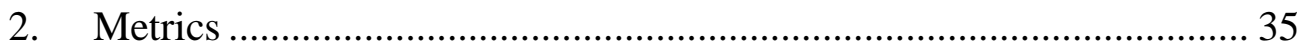

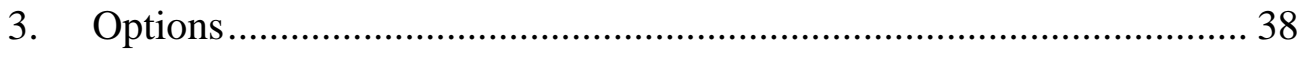

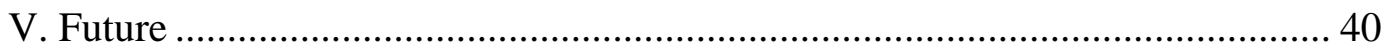

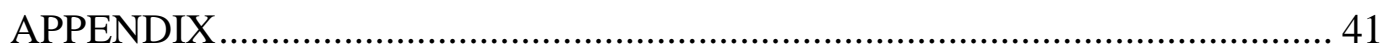

Appendix A. Notation Summary .......................................................... 42

Appendix B. Top Ten Most Valuable QML Patents .................................... 43 


\section{Quantum Machine Learning: A Patent Review}

\section{INTRODUCTION}

Machine learning technology is affecting industries across the economy including law, transportation, and defense. ${ }^{1}$ In the legal industry, technology assisted review is changing the discovery process. ${ }^{2}$ In corporate litigation, millions of documents often require searching and examination for relevance. ${ }^{3}$ As such, clients call on litigators to establish e-discovery relevancy hypotheses and to implement predictive coding models for discovering electronic information. ${ }^{4}$ In other words, algorithms learn what documents are relevant by analyzing and replicating the decisions of real attorneys. ${ }^{5}$

The driving force for machine learning technology is "the realization that every piece of information can be represented as numbers." ${ }^{\prime 6}$ One problem with classical machine learning systems is that data processing is computationally expensive. ${ }^{7}$ In other words, processing the world's information with machine learning algorithms takes a tremendous amount of computational power. ${ }^{8}$ Quantum

\footnotetext{
${ }^{1}$ Emily Berman, A Government of Laws and Not of Machines, 98 B.U. L. REV. 1277, 12781279 (2018), http://www.bu.edu/bulawreview/files/2018/10/BERMAN.pdf (defining "machine learning" as "a strand of artificial intelligence that sits at the intersection of computer science, statistics, and mathematics, and it is changing the world."); see also Jeanne C. Fromer, Machines as the New Oompa-Loompas: Trade Secrecy, the Cloud, Machine Learning, and Automation, N.Y.U. L. REv, 706, 720 (2019), https://papers.ssrn.com/sol3/papers.cfm?abstract_id=3359746 ("In recent years, [machine learning] techniques have been among the most successful and prominent ways of imbuing computers with artificial intelligence, or human-like cognitive abilities.").

${ }^{2}$ See Sara Metzler, Moving Discovery Forward in the Technology Age, GEO. J. LEGAL ETHICS 1153 (2016).

${ }^{3}$ As a result, many law firms submit to costly contracts for document review systems, allowing AI to improve the efficiency with which documents are reviewed. See Michael Simon, et. al., Lola v. Skadden and the Automation of the Legal Profession, 20 YALE J.L. \& TECH. 234, 254 (2018); see also Chris D. Birkel, The Growth and Importance of Outsourced E-Discovery: Implications for Big Law and Legal Education, 38 J. LEGAL PROF. 231 (2014).

${ }^{4}$ KeVIN D. Ashley, ARTIFICIAL InTELLIGENCE AND LEgAl ANALYTICS 240-42 (2017).

${ }^{5}$ See id.

${ }^{6}$ ETHEM ALPAYDIN, MACHINE LEARNING 2 (2016); see also JAMES W. CORTADA, INFORMATION AND THE MODERN CORPORATION 2 (2011) (illustrating that "[d]ata come in many forms ... Data are facts, such as names and numbers."); see also PAUL E. CERUZZI, COMPUTING: A CONCISE HISTORY 103 (2012).

${ }^{7}$ See Brian S. Haney, The Perils and Promises of Artificial General Intelligence, 45 J. LEGIS. 151, 162 (2018).

${ }^{8}$ See Ekaterina Gonina, A Framework for Productive, Efficient and Portable Parallel Computing 1 (Fall 2013) (unpublished Ph.D dissertation, University of California, Berkeley), https://escholarship.org/uc/item/7hs0x0mp (explaining that the need for increased processing power is disrupting the software industry); see also MAXIM LAPAN, DEEP REINFORCEMENT LEARNING HANDS-ON 125 (2018).
} 
computing offers a solution to this problem. Quantum machine learning software makes use of quantum algorithms as part of a larger implementation. ${ }^{9}$

This Article proceeds in four parts. Part II provides background on quantum hardware technologies and the developments making QML possible. Part III explains the formal frameworks for QML, drawing on patents and research to define and review the state-of-the-art. Part IV surveys the patent landscape for QML, modeling datasets, analyzing legal claims, and exploring valuation models. Finally, Part V discusses future considerations for QML technologies and patents.

\section{QUANTUM HARDWARE}

A quantum computer is a physical system harnessing quantum effects for computation. ${ }^{10}$ Quantum computers differ from classical computers in the way they process information. ${ }^{11}$ Classical computers process information with bits - a binary representation. ${ }^{12}$ Quantum computers process information with qubitsrepresenting information in a complex vector space. ${ }^{13}$

\footnotetext{
${ }^{9}$ Mohammad H. Amin, et. al., Quantum Boltzmann Machine, 8 PHYSICAL ReV. X 021050-1 (2016) (proposing a quantum probabilistic model for machine learning based on a Boltzmann distribution of a quantum Hamiltonian, a Quantum Boltzmann Machine).

${ }^{10}$ Aleksey K. Fedorov, et. al., Comment, Quantum Computers Put Blockchain Security at Risk, 563 NATURE INT'L J. SCI. 465, 466 (2018); see also U.S. Patent No. 9,779,360 col. 1 1. 11-21 (filed June 30, 2016); U.S. Patent No. 9,432,024 col. 1 1. 16-44 (filed Sept. 30, 2014).

${ }^{11}$ A. M. Turing, On Computable Numbers, with an Application to the Entscheidungsproblem, 42 PROC. LONDON MATHEMATICAL SOC.'Y 230, 230 (1936) (explaining how classical computers process information); see also U.S. Patent No. 10,474,960 col. 1 1. 9-15 (filed Oct. 25, 2018).

${ }^{12}$ CERUZZI, supra note 6.

${ }^{13}$ See Chris BernhardT, QuANTUM COMPUTING For EVERYone 38 (2019); see also Eleanor Rieffel \& Wolfgang Polak, An Introduction to Quantum Computing for Non-Physicists, 32 ACM COMPUTING SURVEYS 306 (2000) (defining qubit as "a unit vector in a two- dimensional complex vector space for which a particular basis, denoted by $\{\| 0\rangle, \| 1\rangle\}$, has been fixed.").
} 


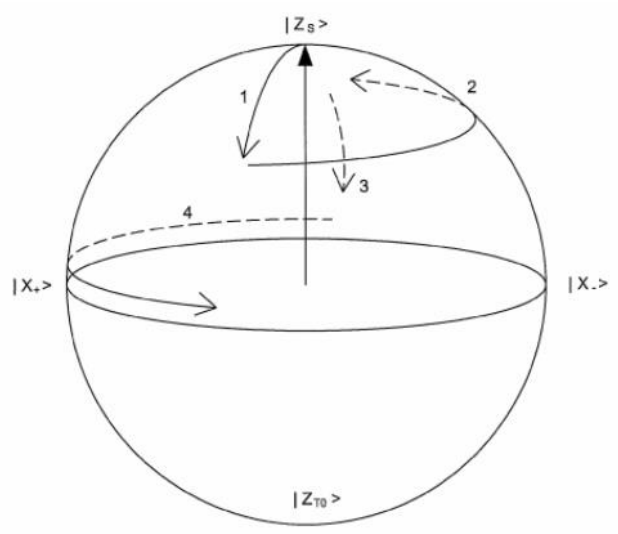

Figure $1^{14}$

To illustrate, Figure 1 is a patent drawing for a qubit. The qubit is an innovation improving the efficiency and power of classical computing methodologies with quantum mechanics. ${ }^{15}$ A qubit may represent a zero, one, or zero and one simultaneously in a state of superposition. ${ }^{16}$ This representation is a complex vector space, rather than Boolean binary, which allows for faster computing and less electrical power consumption compared to its classical counterpart. ${ }^{17}$ The mathematical abstraction is intended to mirror the difference between classical and quantum states in physics. ${ }^{18}$ Commonly, there are two different types of quantum computers, ${ }^{19}$ adiabatic quantum computers and gate model quantum computers. ${ }^{20}$

${ }^{14}$ U.S. Patent No. 9,126,829 fig.5 (filed Jan. 13, 2012).

${ }^{15}$ See U.S. Patent No. 9,400,499 col. 1 1. 35-38; 45-56 (filed Oct. 2, 2015).

${ }^{16}$ Peter M. Kogge \& Jonathan Baker, University of Notre Dame, Quantum Computing Introduction (Fall 2017) (presentation available at https://www3.nd.edu/ kogge/courses/cse30151fa17/Public/Lectures/QC-JMB-edits.pdf). Superposition refers to electrons simultaneously existing in several different quantum states. Quantum Superposition, JOINT QUANTUM INST. (last visited Nov. 4, 2020), https://jqi.umd.edu/glossary/quantum-superposition.

${ }^{17}$ Brian S. Haney, Blockchain: Post-Quantum Security \& Legal Economics, 24 N.C. BANKING INST. 117, 130-131 (2020) [hereinafter "Blockchain"].

${ }^{18}$ LeONARD Susskind \& ART FRIEDMAN, QUANTUM MeChanics: The TheORETICAL Minimum 2 (2014); see also U.S. Patent No. 10,417,574 (filed Nov. 4, 2014).

${ }^{19}$ Recent research indicates a third variant is developing, ion trap quantum computers. See U.S Patent No. 9,858,531 (filed Aug. 1, 2014); U.S Patent No. 7,411,187 (filed May 23, 2006).

${ }^{20}$ Ehsan Zahedinejad \& Arman Zaribafiyan, Combinatorial Optimization on Gate Model Quantum Computers: A Survey 1 (Aug. 16, 2017) (unpublished manuscript), https://arxiv.org/abs/1708.05294. 
Adiabatic quantum computers ("AQCs") are supercomputers harnessing quantum state evolution to perform computation. ${ }^{21}$ For computation, AQCs use the Adiabatic Theorem, ${ }^{22}$ which contains two elements, the Ising Model and a traverse magnetic field. ${ }^{23}$ The Ising Model is used in statistical mechanics, where the relationships between binary variables are represented by couplings. ${ }^{24}$ Further, the Ising Model uses a Hamiltonian ${ }^{25}$ energy measurement function to explain a quantum system's total energy. ${ }^{26}$ The input for the Hamiltonian function is the system's state. ${ }^{27}$ The output is the system's energy measurement. ${ }^{28}$ In other words, the Hamiltonian returns the energy measurement for the particular state. ${ }^{29}$

${ }^{21}$ U.S. Patent No. 7,135,701 col. 1 1. 33-55 (filed Mar. 28, 2005); See also U.S. Patent No. 6,649,929 (filed May 16, 2002).

22 See U.S. Patent No. 7,418,283 (filed Mar. 28, 2005).

${ }^{23}$ See Augusto Cesar Lobo, et al., Geometry of the Adiabatic Theorem (June 8, 2012) (unpublished manuscript), https://arxiv.org/pdf/1112.4442.pdf.

${ }^{24}$ U.S. Patent No. 10,339,466 (filed Sept. 11, 2014); see generally Tameem Albash \& Daniel A. Lidar, Adiabatic Quantum Computing (Feb. 2, 2018) (unpublished manuscript), https://arxiv.org/abs/1611.04471 (presenting an account of many of the developments in the adiabatic quantum computing field).

${ }^{25}$ See U.S. Patent No. 10,037,493 col 1. 1. 12-16; $46-50$ (filed Oct. 21, 2014). In quantum mechanics, the Hamiltonian controls a systems evolution through the time-dependent Schrödinger equation, seen below. SUSSKIND \& FRIEDMAN, supra note 19, at 273.

$$
i \hbar \frac{\partial|\Psi\rangle}{\partial t}=\mathrm{H}|\Psi\rangle
$$

${ }^{26}$ SUSSKIND \& FRIEDMAN, supra note 18, at 274.

27 ' 701 Patent.

${ }^{28}$ The Ising Model is defined:

$$
H_{s}(s)=-\frac{1}{2} \sum_{i} \Delta(s) \sigma_{i}^{x}+\varepsilon(s)\left(-\sum_{i} h_{i} \sigma_{i}^{Z}+\sum_{i<j} J_{i j} \sigma_{i}^{Z} \sigma_{j}^{z}\right) .
$$

Here, $H_{s}(s)$ is the system's energy measurement. The Initial Hamiltonian is defined,

$$
-\frac{1}{2} \sum_{i} \Delta(s) \sigma_{i}^{x}
$$

which is the lowest energy state where all qubits are in a superposition of all states. And, the Final Hamiltonian is defined:

$$
\varepsilon(s)\left(-\sum_{i} h_{i} \sigma_{i}^{z}+\sum_{i<j} J_{i j} \sigma_{i}^{z} \sigma_{j}^{z}\right),
$$

which is the lowest energy state for the system. In essence, the Hamiltonian is the sum of the Initial Hamiltonian and the Final Hamiltonian. See U.S. Patent No. 10,452,990 (filed Nov. 28, 2017).

${ }^{29}$ See Amin, supra note 9, at 2. 


\section{Quantum Machine Learning: A Patent Review}

In addition to the Ising Model, AQCs second essential element is a traverse magnetic field, which can be manipulated to solve optimization problems. ${ }^{30}$ During computation, each qubit begins in a flux superposition encoded in a circular magnetic field. ${ }^{31}$ Then a magnetic field is applied to the qubits and the qubits move toward a binary state. ${ }^{32}$ AQCs harness natural quantum state evolution to solve optimization and sampling problems. ${ }^{33}$ More specifically, AQCs measure quantum state evolution with a Hamiltonian function, manipulating a magnetic field to perform computation. ${ }^{34}$ However, one potential drawback is that AQCs are arguably incapable of scaling to a universal quantum computer. ${ }^{35}$

The second type of quantum computer is the Gate Model Quantum Computer ("GMQC"). ${ }^{36}$ In contrast to AQCs, which utilize a quantum state's natural evolution, GMQCs manipulate quantum state evolution. ${ }^{37}$ The GMQC has two conceptual elements, the quantum circuit and gate transformation. In other words, GMQCs uses a circuit, replacing classical gates with quantum equivalents. ${ }^{38}$ However, a quantum circuit can process information in a manner significantly different from binary digital techniques based on transistors. ${ }^{39}$ In the circuit-based model, qubits remain coherent over time periods much longer than the single-gate time. ${ }^{40}$ For GMQCs, the main goal is to control and manipulate quantum state evolution over time with gate transformations. ${ }^{41}$

\footnotetext{
${ }^{30}$ See U.S. Patent No. 7,877, 333 (filed Sept. 5, 2007).

${ }^{31}$ See U.S. Patent No. 7,788,192 (filed Jan. 22, 2007).

${ }^{32}$ See '701 Patent.

${ }^{33} \mathrm{See}$ '333 Patent.

${ }^{34} \mathrm{See}$ '493 Patent.

35 "AQC is universal in that it is able to convert any input state into any output state. However, unlike the circuit model of quantum computing, there is no application of a predetermined set of one- and two-qubit unitary gates at precise times." '283 Patent col. 7 1. 51-56; see also Joel M. Gottlieb, North Carolina State University, Introduction to the Physics of D-Wave and Comparison to Gate Model (March 20, 2018).

${ }^{36}$ See '024 Patent.

37 See U.S. Patent No. 10,439,735 (filed Mar. 7, 2017).

38"Analogous to how classical algorithms can be built from a universal logic gate, such as a NAND gate, all quantum algorithms can be constructed from a universal set of quantum gates." '024 Patent, col. 1 1. 21-24.

39 '960 Patent; see generally Mihika Prabhu, Towards Optimal Capacity-Achieving Transceivers with Photonic Integrated Circuits (Jan.31, 2018), https://dspace.mit.edu/handle/1721.1/115725.

${ }^{40}$ U.S Patent No. 8,504,497 (filed Jul. 28, 2010) (issued August 6, 2013).

${ }^{41}$ See Artur Eckert, et al., Basic Concepts in Quantum Computation 4 (Feb. 1, 2008) (unpublished manuscript), https://arxiv.org/abs/quant-ph/0011013v1 (discussing qubit control toward a target state).
} 
A quantum gate is a state transformation acting on qubits. ${ }^{42}$ Some sequences of quantum gates are called quantum gate arrays. ${ }^{43}$ In quantum information processing, gates are mathematical abstractions useful for describing quantum algorithms. ${ }^{44}$ For example, the controlled-NOT $\left(C_{n o t}\right)$ gate ${ }^{45}$ operates on two qubits by changing the second bit if the first bit is one, leaving the bit unchanged otherwise. ${ }^{46}$ The GMQC's main advantage is the potential to scale to a universal quantum computer-a computer that can simulate any other quantum computer. ${ }^{47}$ But, GMQCs are slower to scale than AQCs, meaning practically GMQCs have less qubits. ${ }^{48}$

\section{QUANTUM MACHINE LEARNING}

Quantum Machine Learning ("QML”) refers to a specific type of quantum software application that integrates quantum hardware architectures with classical and quantum algorithms for machine learning. ${ }^{49}$ Machine learning is a process where computational matter rearranges itself according to logical rules to achieve goals. ${ }^{50}$ According to Maria Schuld, "[t]he new research field of quantum machine

${ }^{42}$ See ElEANOR RIEFFel \& WOLFGANG POLAK, QUANTUM COMPUTING 74 (2014); see also Eckert, supra note 41 at 4 ("A quantum logic gate is a device which performs a fixed unitary operation on selected qubits in a fixed period of time and a quantum network is a device consisting of quantum logic gates whose computational steps are synchronized in time.").

${ }^{43}$ See U.S. Patent No. 9,892,365 (filed Feb. 27, 2015) (issued Feb. 13, 2018); see also U.S. Patent No. 10,268,232 (filed June 2, 2017) (issued Apr. 23, 2019) (discussing quantum gate array applications for developing neural networks).

${ }^{44}$ RIEFFEL \& POLAK, supra note 42, at 74.

45،735 Patent ("In computing science, the controlled NOT gate (also C-NOT or CNOT) is a quantum gate that is an essential component in the construction of a quantum computer.").

${ }^{46}$ See RIEFFEL \& POLAK, supra note 42, at 77.(2014). The $C_{\text {not }}$ gate's importance in quantum computing stems from its ability to change the entanglement between two qubits. The $C_{\text {not }}$ gate is defined:

$$
C_{n o t}=|0\rangle\langle 0|\otimes I+| 1\rangle\langle 1| \otimes X .
$$

Here, $I$ is an identity transformation, and $X$ is negation, and $\otimes$ is the tensor product. Interestingly, $C_{n o t}$ is unitary and is its own inverse.

47 '192 Patent.

${ }^{48}$ Ehsan Zahedinejad \& Arman Zaribafiyan, Combinatorial Optimization on Gate Model Quantum Computers: A Survey 3 (Aug. 16, 2017) (unpublished manuscript),

https://arxiv.org/abs/1708.05294 ("Over the past decade, there has been a great deal of progress in designing adiabatic quantum devices, with the D-Wave 2000Q quantum computing machine, with more than two thousand qubits, being the latest quantum adiabatic optimizer.").

${ }^{49}$ Emily Berman, A Government of Laws and Not of Machines, 98 B.U. L. REV. 6 (2018).

${ }^{50} I d$. at 1277-78 (explaining that machine learning is a strand of artificial intelligence that sits at the intersection of computer science, statistics, and mathematics, and it is changing the world). 
learning might offer the potential to revolutionize future ways of intelligent data processing." ${ }^{51}$ Part III analyzes three QML system types: (1) predictive graphs; (2) intelligent agents; and (3) quantum convergent.

\section{A. Predictive Graphing}

The first type of quantum machine learning system is predictive graphing. The central goal for predictive graph models is pattern recognition in which a machine draws inferences from a set of training data, subsequently mapping new inputs to corresponding outputs. ${ }^{52}$ Many quantum graphing models use linear algebra, scaling Boolean logic for abstract reasoning. ${ }^{53}$ Predictive graphing models include Quantum Neural Networks ("QNNs") and Quantum Boltzmann Machines (“QBMs").

\section{QUANTUM NEURAL NETWORKS}

A QNN is an organized structure of interconnected neurons, capable of association as a graph with nodes and edges. ${ }^{54}$ The network's interconnected neurons are modeled with weight coefficients that are adjusted through a learning process until a model is optimized for performance. ${ }^{55}$ Importantly, QNNs are universal function approximators: they can approximate any function with desired accuracy given enough neurons. ${ }^{56}$ Since all that information can be represented as

\footnotetext{
${ }^{51}$ Maria Schuld, et al., An introduction to quantum machine learning 2 (2014) (unpublished manuscript), https://arxiv.org/pdf/1409.3097.pdf.

${ }^{52}$ Maria Schuld, et al., Prediction by linear regression on a quantum computer 1 (2016) (unpublished manuscript), https://arxiv.org/abs/1601.07823v2; see also Maria Schuld, et al., Measuring the similarity of graphs with a Gaussian Boson Sampler 9 (2019), https://journals.aps.org/pra/abstract/10.1103/PhysRevA.101.032314. ("We proposed a new type of feature extraction strategy for graph-structured data based on the quantum technique of Gaussian Boson Sampling.").

${ }^{53}$ Fromer, supra note 1, at 720 ("The critical ingredients of machine learning are relevant data and statistical techniques.").

${ }^{54}$ Maria Schuld, et al., The quest for a Quantum Neural Network 1 (2014) (unpublished manuscript), https://arxiv.org/abs/1408.7005 (“Quantum Neural Networks (QNNs) are models, systems or devices that combine features of quantum theory with the properties of neural networks.") [hereinafter "Quest for a Quantum Neural Network"].

${ }^{55}$ U.S. Patent No. 10,229,355 (filed Apr. 13, 2016) (issued Mar. 12, 2019).

${ }^{56}$ Brian S. Haney, AI Patents: A Data Driven Approach, 19 CHI.-Kent J. INTELl. PROP. (forthcoming 2020), https://papers.ssrn.com/sol3/papers.cfm?abstract_id=3527154 [hereinafter "AI Patents"].
} 
numbers, the QNN's ability to generalize to new information is a critical component for deep learning. ${ }^{57}$ Theoretically, a QNN can process any information. ${ }^{58}$

QNNs map differently to different hardware depending on the physical substrate. For example, QNNs may be mapped to an AQC with a Chimera Graph architecture. ${ }^{59}$ But, every QNN has an input layer and an output layer. ${ }^{60}$ The process by which data flows from the input layer to the output layer is the network's function. ${ }^{61} \mathrm{~A}$ QNN contains multiple hidden layers between the input and output layer. ${ }^{62}$ The model's depth is defined by the number of hidden layers between the input and output layer. ${ }^{63}$

Each layer of hidden neurons acts as a feature extractor by providing analysis of slightly more complicated features. ${ }^{64}$ Feature extraction is a method of dimensionality reduction - decreasing input attributes - allowing the observable manifestation of hidden features. ${ }^{65}$ The later neurons extract hidden features by

${ }^{57}$ Christa Zoufal, et al., Quantum Generative Adversarial Networks for learning and loading random distributions, 1 (2019), https://www.nature.com/articles/s41534-019-0223-2 ("We demonstrated the application of an efficient, approximate probability distribution learning and loading scheme based on qGANs that requires $\mathcal{O}(\operatorname{poly}(n))$ many gates."); see also ETHEM ALPAYDIN, MACHINE LEARNING 2 (2016).

${ }^{58}$ Olga Russakovsky, et al., Best of both worlds: human-machine collaboration for object annotation (2015), https://ieeexplore.ieee.org/document/7298824 (introducing a model that integrates multiple computer vision models with multiple sources of human input in a Markov Decision Process); see also Lise Getoor, et al., Learning Probabilistic Models of Relational Structure (2001), https://ai.stanford.edu/ koller/Papers/Getoor+al:ICML01.pdf.

${ }^{59}$ Luca Asproni, et al., Accuracy and minor embedding in subqubo decomposition with fully connected large problems: a case study about the number partitioning problem, QUANTUM MACHINE INTEL. (2020), https://doi.org/10.1007/s42484-020-00014-w.

${ }^{60}$ U.S. Patent No. 10,268,232 (filed June 2, 2017) (issued Apr. 23, 2019).

${ }^{61} \mathrm{Id}$.

62 '355 Patent.

${ }^{63}$ Mihika Prabhu, et al., A Recurrent Ising Machine in a Photonic Integrated Circuit (2019) (unpublished manuscript), https://arxiv.org/abs/1909.13877 (experimentally demonstrating a photonic recurrent Ising sampler for probabilistically finding the ground state of an arbitrary Ising problem); see also Serena Yung, et al., Every Moment Counts: Dense Detailed Labeling of Actions in Complex Videos (2017) (unpublished

manuscript), https://arxiv.org/abs/1507.05738 (modeling multiple dense labels benefits from temporal relations within and across classes); Brian S. Haney, Applied Natural Language Processing for Law Practice, 2020 B.C. INTELL. PROP. \& TECH. F. (2020) [hereinafter "Applied Natural Language"].

${ }^{64}$ Quest for a Quantum Neural Network, supra note 54, at 3 ("Computing in artificial neural networks is derived from our neuroscientific understanding of how the brain processes information in order to master its impressive tasks.").

${ }^{65}$ Brian S. Haney, Deep Reinforcement Learning Patents: An Empirical Survey (2020), https://papers.ssrn.com/sol3/papers.cfm?abstractid=3570254. 


\section{Quantum Machine Learning: A Patent Review}

combining the previous features of a slightly larger number of neurons. ${ }^{66}$ Finally, the output layer observes the whole input to produce a final prediction. ${ }^{67}$ In other words, QNNs learn more complicated functions of their initial input when each hidden layer combines the values of the preceding layer. ${ }^{68}$

Consider, U.S. Patent No. 10,417,553, Quantum-assisted training of neural networks ('553 patent), which is assigned to Lockheed Martin. ${ }^{69}$ The 553 ' patent's figure 4 provides a flow model for training neural networks on quantum computers. $^{70}$

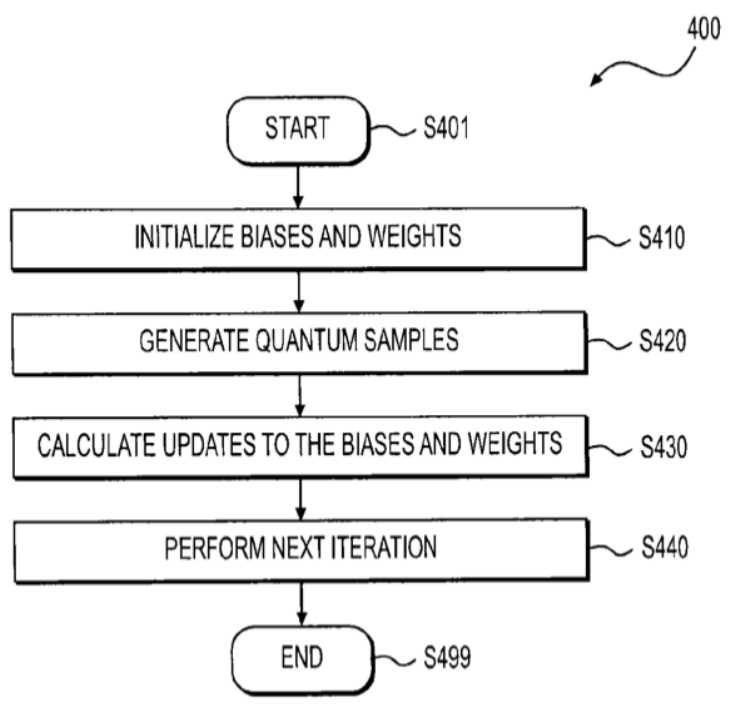

Figure $2^{71}$

Figure 2 is the ' 553 patent's figure 4 . The model illustrates a process for training neural networks using quantum sampling and backpropagation.

\footnotetext{
${ }^{66}$ Anya Tafliovich, Quantum Programming, 2 (2004) (unpublished M.Sc. thesis, University of Toronto) http://citeseerx.ist.psu.edu/viewdoc/download?doi=10.1.1.129.6391\&rep=rep1\&type=pd $\mathrm{f}$ ("In this work the theory of quantum programming is based on probabilistic predicative programming, a recent generalization of the well-established predicative programming, which we deem to be the simplest and the most elegant programming theory known today.").

${ }^{67}$ U.S. Patent No. 8,595,167 (filed Nov. 30, 2010) (issued Nov. 26, 2013).

${ }^{68}$ Schuld, supra note 51 at 2.

${ }^{69}$ U.S. Patent No. 10,417,553 (filed May 1, 2015) (issued Sept. 17, 2019).

${ }^{70} \mathrm{Id}$.

${ }^{71} I d$. ("FIG.4 shows a flow chart of a quantum-assisted training process for training neural networks according to an embodiment of the disclosure. In an embodiment, the neural network to be trained is a deep learning neural network. The process starts at S401 and proceeds to S410.”).
} 
Backpropagation is an algorithm for updating the weights in a neural network, improving accuracy over time. ${ }^{72}$ Backpropagation is how neural networks learn. ${ }^{73}$ Technically, backpropagation's central task is to minimize an error function, which can be computationally expensive on classical hardware. ${ }^{74}$ After consistent iteration, the network converges, capturing a general pattern and allowing the network to generalize about new instances, rather than merely memorizing training data. ${ }^{75}$ The algorithm's ultimate goal is convergence to an optimal network, but probabilistic maximization also provides state-of-the-art performance in real world tasks. ${ }^{76}$ Similar to QNN structure, QBMs are also a graph based model for prediction.

\section{QUANTUM BOLTZMANN MACHINES}

A QBM is a network of symmetrically coupled stochastic binary units. ${ }^{77}$ In other words, a QBM is a model representing a probability distribution over a set of

${ }^{72}$ U.S. Patent No. 10,540,588 (filed June 29, 2015) (issued Jan. 21, 2020).

${ }^{73}$ Paul John Werbos is considered the first person to explore backpropagation through neural networks in his seminal $1974 \mathrm{Ph} . \mathrm{D}$. thesis, The Roots of Backpropagation. One the key contributions of Werbos' work is the idea of backpropagation through time. By applying a temporal element to the process, Werbos showed the utility of neural networks in dynamic control tasks for robotics systems. See PaUl John Werbos, The RoOts of BaCKPropagation From ORDERED DERIVATIVES TO NEURAL NETWORKS AND POLITICAL ForECASTING 279-280 (1994). ${ }^{74} \mathrm{An}$ error function is a measure of the difference between the network's output and the actual value associated with the instance. The error function is minimized through an iterative process, updating the network's weights toward a set of weights capable of generalizing to make accurate predictions for the whole data set, or text corpus. See United States Patent No. 10,346,974 (filed May 18, 2017) (issued July 9, 2019); see also SEbASTIAN RASCHKA, VAHID MIRJALILI, PYTHON MACHINE LEARnING 24, 35-36 (2017); United States Patent No. 10,112,113 (filed Mar. 30, 2016) (issued Oct. 30, 2018).

${ }^{75}$ Fang Liu, Assessment of Bayesian Expected Power via Bayesian Bootstrap 14 (2017) (unpublished manuscript), https://arxiv.org/abs/1705.04366 ("The bootstrap-based procedures will appeal to non-Bayesian practitioners given their analytical and computational simplicity and easiness in implementation."); see also U.S. Patent No. 10,049,301 (filed Aug. 1, 2016) (issued Aug. 14, 2018) (discussing difficulties using policy iteration in practice).

${ }^{76}$ JOHN D. KELLEHER, DEEP LEARNING 215 (2018).

${ }^{77}$ U.S. Patent No. 10,402,743 (filed Oct. 25, 2018) (issued Sept. 3, 2019) (“A Boltzmann Machine (BM) can be described as a graph where each node (or unit) is equipped with a parameter and each edge is equipped with a (coupling) parameter."). The QBM contains a set of visible units:

$$
v \in\{0,1\}^{D} .
$$

Further, the QBM contains a set of hidden units:

$$
h \in\{0,1\}^{P} .
$$


binary variables. ${ }^{78} \mathrm{QBMs}$ use two types of binary variables - visible variables, $v$, and hidden variables, $h .^{79}$ Figure 3 presents a QBM model.

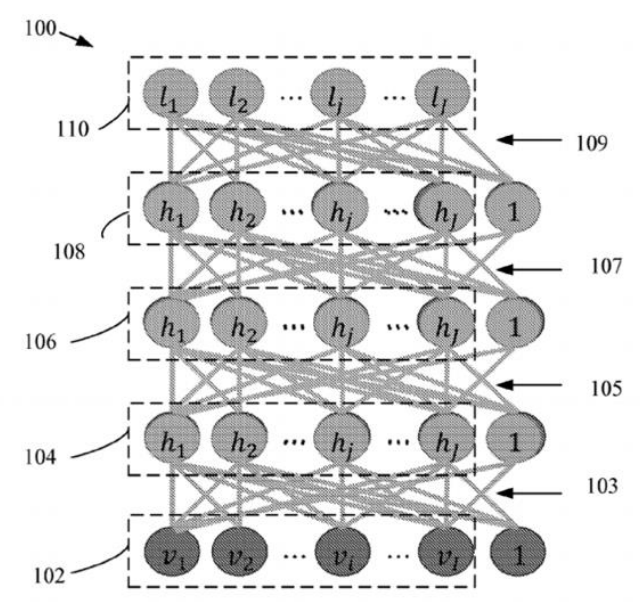

Figure $3^{80}$

The visible variables correspond to the important variables of a system - for example, the inputs and outputs. ${ }^{81}$ The hidden variables enable the encoding of more complex relationships among the visible variables. ${ }^{82}$

There are several QBM variations, for example Restricted Boltzmann Machines ("RBMs") ${ }^{83}$ and Semi-Restricted Boltzmann Machines ("SRBMs"). ${ }^{84}$

\footnotetext{
${ }^{78}$ Fabian Ruehle, Data Science Applications to String Theory, PHYSICS REPORTS 87 (2020).

${ }^{79}$ Volodymyr Mnih, et. al., Conditional Restricted Boltzmann Machines for Structured Output Prediction (2012) (unpublished manuscript), https://arxiv.org/abs/1202.3748 (stating that

Boltzmann machines are particularly well suited for quantum computing architectures because of their heavy reliance on the use of binary variables).

${ }^{80}$ World Patent No. WO 2016/089711 AI fig.3 (filed June 9, 2016). Figure 1 illustrates a deep

Boltzmann machine, with an input layer, three hidden layers, and a visible layer.

81 '466 Patent.

82 ' 553 Patent.

${ }^{83}$ One is the Restricted Boltzmann Machine (RBM). An RBM is a two- layer neural network, where the hidden units are conditionally independent given the visible states. Further, the RBM has no lateral edges with its visible or hidden variables and is modeled as a bigraph graph. A bigraph is a set of graph vertices with two distinct sets. In the RBM, the hidden nodes are not connected to one another. The visible nodes are also not connected to one another. See Mnih supra note 79.

84 '466 Patent. A second variation is the Semi-Restricted Boltzmann Machine. A Semi-RBM is a two-layer neural network, where the hidden variables are in conditional equilibrium with the visible variables. However, the visible units may not be in conditional equilibrium with the hidden variables. In other words, there are connections between the hidden variables, but not the visible
} 
But, both RBMs and SRBMs are shallow networks, with only two layers. ${ }^{85}$ Therefore, the most powerful QBM model variant is the Deep Boltzmann Machine ("DMB"). The DBM is QBM integrated with a QNN in which each layer captures a different abstraction of information. ${ }^{86}$ In the DBM, additional hidden nodes are added to create a multi-layered network, deriving deeper abstractions for statistical inference and meaning. ${ }^{87}$ As such, deep learning algorithms can be run on quantum hardware by re-framing neural network architectures through a Boltzmann Formalism. ${ }^{88}$ Thus, both QNNs and QBMs provide opportunity for quantum speedup as machine learning converges with quantum hardware.

\section{B. INTELLigent AgENTS}

In the 1999 film The Matrix, AI agents named Mr. Smith take over the world, while humanity is forced to fight these intelligent machines at great sacrifice. ${ }^{89}$ Perhaps coincidentally, the terminology has evolved into the machine learning and AI literature twenty years later. Intelligent agents are machines, which learn and take actions to achieve goals. Reinforcement learning is a machine learning system for creating and controlling intelligent agents. ${ }^{90}$ The main idea is to train an agent to learn to take intelligent actions through a reward system. ${ }^{91}$

\section{REINFORCEMENT LEARNING}

Reinforcement learning algorithms contain three elements: (1) model: the description of the agent-environment relationship; ${ }^{92}$ (2) reward: the agent's goal $;{ }^{93}$ and (3) policy: the way in which the agent takes actions. ${ }^{94}$ For reinforcement

\footnotetext{
variables. In the Semi-RBM, the hidden nodes are connected to one another, but the visible nodes are not.

${ }^{85}$ Id.

${ }^{86}$ Ruehle, supra note 78 , at 90.

${ }^{87}$ Brian S. Haney, Quantum Patents, 27 B.U. J. SCI. \& TECH. L. __ (2020) (forthcoming), https://papers.ssrn.com/sol3/papers.cfm?abstract_id=3554925.

${ }^{88}$ For example, QBM's may be executed on D-Wave's AQC. See '553 Patent.

89 THE MATRIX (Warner Bros. Pictures 1999).

90 MYKel J. KOCHENDERFER, DECISION MAKING UNDER UNCERTAINTY 77 (2015); see also U.S. Patent No. 10,346,741 (filed July 9, 2019).

${ }^{91}$ Eugene CharniaK, InTROdUCTION TO DEEP LEARNING 113 (2018).

92 Katerina Fragkiadaki, Carnegie Mellon School of Computer Science, Deep Q Learning, (Fall 2018) (presentation available at https://www.cs.cmu.edu/ katef/DeepRLFall2018/lecture_DQL_katef2018.pdf).

${ }^{93}$ LAPAN, supra note 8 , at 3.

${ }^{94}$ U.S. Patent No. 9,298,172 (issued Mar. 29, 2016); see also Fragkiadaki, supra note 92.
} 
learning systems, the environment ${ }^{95}$ represents the problem. ${ }^{96}$ Formally, reinforcement learning is described through an agent-environment interaction, with the Markov Decision Process ("MDP"). ${ }^{97}$ For example, in financial trading, the environment is made up of states for moments in time in which a portfolio of stocks exists. ${ }^{98}$ In the quantum context, the environment is a Quantum Observable Markov Decision Process ("QOMDP"). ${ }^{99}$ In other words, the state-space is described with a Hamiltonian, rather than a classical state measurement. ${ }^{100}$

\section{QUANTUM MARKOV MODELS}

The agent is an algorithm solving the environment or problem by taking action. ${ }^{101}$ In an QOMDP, the interaction begins when an agent chooses an action in the environment's initial quantum state. ${ }^{102}$ The model continues to the next quantum state, where the agent receives a reward and a set of actions from which to choose - the agent selects an action, and the environment returns a reward and the next quantum state. ${ }^{103}$ Ultimately, in reinforcement learning, an agent learns to take goal-oriented, or intelligent actions. ${ }^{104}$

\footnotetext{
${ }^{95}$ Ramin Ayanzadeh, et al., Reinforcement Quantum Annealing: A Quantum-Assisted Learning Automata Approach 8 (2020) (unpublished manuscript), https://arxiv.org/abs/2001.00234 ("In this study, we introduced a novel scheme - called reinforcement quantum annealing (RQA) - that leverages reinforcement learning (more specifically learning automata) to ENHANCE the quality of results, attained by the quantum annealers."); see also U.S. Patent No. 10,396,919 (issued August 27, 2019).

${ }^{96}$ LAPAN supra note 8 at 8; see also U.S. Patent No. 9,298,172 (issued Mar. 29, 2016).

${ }^{97}$ Jeanne C. Fromer, Learning Optimal Discourse Strategies in a Spoken Dialogue System 40 (1998) (Masters Thesis, Massachusetts Institute of Technology) (available at https://dspace.mit.edu/bitstream/handle/1721.1/47703/42306186-

MIT.pdf?sequence=2\&isAllowed=y) ("These algorithms can calculate optimal discourse policies for Markov decision problems (MDPs), accessible, stochastic environments with a known transition model.").

${ }^{98}$ LAPAN, supra note 8 at $20-21$.

${ }^{99}$ Jennifer Barry, et al., Quantum Partially Observable Markov Decision Processes, American Physical Society, MIT OPEN ACCESS ARTICLES 1 (2014), https://journals.aps.org/pra/abstract/10.1103/PhysRevA.90.032311.

${ }^{100}$ U.S. Patent No. 9,881,256 (issued Sep.7, 2017); see also Schuld, supra note 51, at 2.

${ }^{101}$ The agent may iterate over the action space, selecting actions according to a defined policy. See ChARNIAK, supra note 91, at 113; see also '741 Patent; U.S. Patent No. 10,498,855 (issued Dec. 3, 2019).

${ }^{102}$ Barry et al., supra note 99, at 4 (explaining that in a QOMDP, the agent can track of the quantum state using each time it takes an action and receives an observation).

${ }^{103}$ CHARNIAK, supra note 91, at 113.

${ }^{104}$ Barry et al., supra note 99, at 2; see also U.S. Patent No. 10,423,129 (issued Sep. 24, 2019).
} 
The goal for an agent in a QOMDP is to maximize its expected reward during the episode. ${ }^{105}$ The agent's goal is to maximize its total reward, rather than the reward for its immediate state. ${ }^{106}$ The agent's policy determines the value the agent returns over the course of an episode. ${ }^{107} \mathrm{~A}$ policy is a mapping from states to probabilities for selecting actions. ${ }^{108} \mathrm{~A}$ policy is the way in which an agent makes decisions. ${ }^{109}$ Therefore, the goal for quantum reinforcement learning is to identify and select the policy which maximizes expected reward for an agent acting in a quantum environment. ${ }^{110}$ As these models converge with predictive quantum graphs on quantum hardware, Mr. Smith comes to life with only time to scale.

\section{Quantum CONVERgence}

New technologies often represent a convergence of many different streams of techniques, devices, and machines, each coming from its own separate historical avenue of development. ${ }^{111}$ For example, the smart phone manifested as a convergence of personnel computers and mobile phones. ${ }^{12}$ A leading scholar at the intersection of patents and technical convergence, University of Cagliari Professor Elona Marku explains, ${ }^{113}$ convergence is "the merging or overlapping of different

\footnotetext{
${ }^{105}$ Episode refers to the total experience of an agent progressing through an environment a terminal state. See KOCHENDERFER, supra note 90 at 77; see also '855 Patent.

106 CHARNIAK, supra note 91, at 113.

${ }^{107}$ Formally, the policy is represented as $\pi$. System, method and device for predicting navigational decision-making behavior, U.S. Patent No. 8,478,642 (issued July 2, 2013); see also U.S. Patent No. 10,146,286 (issued Dec. 4, 2018); KoCHENDERFER, supra note 90 at 79-80; U.S. Patent No. 10,146,286 (issued Dec. 4, 2018).

${ }^{108}$ KoCHENDERFER, supra note 90, at 80; see also U.S. Patent No. 8,060,454 (issued Nov. 15, 2011).

${ }^{109}$ KOCHENDERFER, supra note 90, at 80.

110 Barry, et al., supra note 99, at 2.

111 CERUZZI, supra note 6, at 74-6.

${ }^{112}$ Interestingly, in 2009 Nokia and Samsung paid a small semiconductor firm in King of Prussia, Pennsylvania called InterDigital a combined \$653 million over a portfolio of patents for smart phone technology. See John PALfrey, InTEll. Prop. Strategy 18 (MIT Press 2012); see also In re Arbitration Between Interdigital Commc'ns Corp. \& Samsung Elecs. Co., Ltd., 528 F. Supp. 2d 340 (S.D.N.Y. 2007); InterDigital Commc'ns Corp. v. Nokia Corp., 407 F. Supp. 2 d 522 (S.D.N.Y. 2005).

${ }^{113}$ ELONA MARKU, ET AL., Business TRANSFORMATIONS IN THE ERA OF DigitaliZATIOn, Mapping Innovation in the Digital Transformation Era: The Role of Technology Convergence, 163 (IGI Global 2019),

https://www.researchgate.net/publication/329874675_Mapping_Innovation_in_the_Digital_Transf ormation_Era_The_Role_of_Technology_Convergence ("This is consistent with the technological convergence paradigm, two or more technologies move together in the technological space, overlapping or merging with each other while generating new innovations.").
} 


\section{Quantum Machine Learning: A Patent Review}

fields of technology as a result of scientific and technological progress."114 At the bleeding edge of machine learning, the Deep Q-Network ("DQN") algorithm, represents the deep learning and reinforcement learning convergence. A step further, the DQN's implementation on quantum hardware, the Quantum QNetwork is a software-to-hardware convergence. ${ }^{115}$

\section{DEEP Q-NETWORK}

DQNs are deep neural networks embedded in the reinforcement learning architecture, representing these two systems' convergence. ${ }^{116}$ The DQN is a critically important deep reinforcement learning algorithm. ${ }^{117}$ The DQN algorithm develops an optimal policy ${ }^{118}$ for an agent with a Q-learning algorithm. ${ }^{119}$ QLearning is a model-free reinforcement learning technique, a trial-and-error algorithm. ${ }^{120}$ As NYU Law Professor Jeanne Fromer explains, "Q-learning seems especially suited for learning the most successful actions in a particular state for a system."121

\footnotetext{
${ }^{114} I d$. at 163 ("Consistent with this stream of research, we conceive technological convergence as the merging or overlapping of different fields of technology as a result of scientific and technological progress.").

${ }^{115}$ Schuld et al., supra note 51 at 14 ("Hidden Markov models are Markov processes for which the states of the system are only accessible through observations.").

116 See generally LESLIE PACK KAELBLING, LEARNING IN EMBEDDED SYSTEMS (1990).

117 U.S. Patent No. 10,032,281 (issued July 24, 2018); see also Yuval Tassa, et. al., DeepMind Control Suite, 12 (2018) (unpublished manuscript), https://arxiv.org/abs/1801.00690 (explaining that the Deep Mind Control Suit is a set of tasks for benchmarking continuous RL algorithms developed by Google Deep Mind); U.S. Patent No. 10,296,830 (issued May 21, 2019).

118 The optimal policy is the best method of decision making for an agent with the goal of maximizing reward. See KOCHENDERFER, supra note 90, at 81.

${ }^{119}$ It does so by using Q-learning to learn a data labeling policy on a small labeled training dataset, and then using this to automatically label noisy web data for new visual concepts. See Serena Yeung, et al., Learning to Learn from Noisy Web Videos, Proceedings of the IEEE Conference on Computer Vision and Pattern Recognition 5154-5162 (2017),

http://openaccess.thecvf.com/content_cvpr_2017/html/Yeung_Learning_to_Learn_CVPR_2017_p aper.html.

${ }^{120}$ Leslie Pack Kaelbling, et al., Reinforcement Learning: A Survey, J. OF ARTIFICIAL INTEL. RSCH. 253 (1996), http://www.cse.msu.edu/ cse841/papers/kaelbling.pdf.

121 Fromer, supra note 97 at 40, 43 (explaining "Q-learning seems especially suited for learning the most successful actions in a particular state for a system. [.. .] These algorithms can calculate optimal discourse policies for Markov decision problems (MDPs), accessible, stochastic environments with a known transition model.").
} 


\section{Journal of Law, Technology \& the Internet - Vol. 12}

The DQN algorithm combines Q-learning ${ }^{122}$ with a neural network to maximize an agent's reward. ${ }^{123}$ The DQN algorithm's most important aspect is the Bellman Equation. ${ }^{124}$ The Bellman Equation does two things: it (1) defines the optimal policy; and (2) forces the agent to consider the reward in its present state as greater compared to rewards in future states. ${ }^{125}$ The Bellman Equation is a slower algorithm in practice and can be computationally expensive. Thus, a neural network is used as an approximator for a state-action value function, allowing for more efficient programming and model development. ${ }^{126}$

The DQN is an off-policy algorithm, meaning it uses data to optimize performance. ${ }^{127}$ But, one problem with training DQN algorithms, and off-policy deep reinforcement learning algorithms more generally, is that they are computationally expensive. In other words, these algorithms require massive

${ }^{122}$ U.S. Patent No. 10,049,301(issued Aug. 14, 2018); see also LAPAN, supra note 8, at 144.

${ }^{123}$ PAUl JohN Werbos, THE ROOTS OF BACKPROPAGATION From ORDERED DERIVATIVES TO NEURAL NETWORKS AND POLITICAL FoRECASTING 306-307 (1994).

${ }^{124}$ The algorithm continues perpetually until the convergence of the Q-value function. The convergence of the Q-value function represents $Q^{*}$ and satisfies the Bellman Equation, defined:

$$
Q^{*}(s, a)=E_{s^{\prime} \sim \varepsilon}\left[r+\gamma \max _{a^{\prime}} Q^{*}\left(s^{\prime}, a^{\prime}\right) \mid s, a\right] .
$$

Here, $E_{s^{\prime} \sim \mathcal{E}}$ refers to the expectation for all states, $r$ is the reward, $\gamma$ is a discount factor. Additionally, the $\max$ function describes an action at which the Q-value function takes its maximal value for each state-action pair. An agent's optimal policy $\pi^{*}$ corresponds to taking the action in each state defined by $Q^{*}$. In short, the Bellman Equation expresses the relationship between the value of a state and the values of its successor states. The algorithm continues perpetually until the Q-value function's convergence with an approximate maximum. See '454 Patent (claim 14 and claim 23 both discuss applications of Bellman equations for optimality).

125 See Jordi Torres, The Bellman Equations, Deep Reinforcement Learning Explained 8 (June 11, 2020), https://towardsdatascience.com/the-bellman-equation-59258a0d3fa7.

${ }^{126}$ However, one issue that arises is that the value of $Q(s, a)$ must be computed for every stateaction pair, which may be computationally infeasible. For example, computing the value of every state-action pair, where the raw input is pixels in an Atari game would require tremendous computational power. One solution is to use a function approximator to estimate the Q-value function:

$$
Q(s, a ; \emptyset) \approx(s, a)
$$

Here, $\varnothing$ represents the function parameters. Thus, the Q-value correlates with an optimal policy, telling the agent which actions to take in any given state. See U.S. Patent Application No. 14/097 (filed Dec. 5, 2013), https://patents.google.com/patent/US20150100530A1/en.

${ }^{127}$ Hado van Hasselt, Arthur Guez, \& David Silver, Deep Reinforcement Learning with QLearning, GOOGLE DEEPMIND 2098 (2018). 
amounts of computing power. ${ }^{128}$ As such, these system's intersection with quantum computers provides better way to develop AI technology.

\section{QUANTUM Q-NETWORK}

Quantum Q-Networks (“QQN") represent the convergence of quantum hardware, reinforcement learning, and deep learning technologies, or more concisely, the convergence of quantum hardware and the DQN. In 2017, a team of quantum researchers published DQN implementations on quantum hardware for the first time. ${ }^{129}$ While the achievement went relatively unnoticed, time will reveal this seminal work. The researchers implemented the QQN to solve $3 \times 5$ grid-world problem. ${ }^{130}$ The team solved the grid-world problem ${ }^{131}$ using various Q-learning methods with the Q-function parametrized by neural networks on an adiabatic quantum computer. ${ }^{132}$

There are various ways in which QQN may evolve in QML research, application, and patents. For example, the network may sample from a quantum processor to optimize action selection, or alternatively, the QQN may integrate a deep Boltzmann machine ${ }^{133}$ within a Markov Decision Process for faster training. Future research will employ these models to scale, solving real world problems with quantum machine learning. Protecting these innovations could mean the difference between market dominance and irrelevance for market firms.

\footnotetext{
128 See Haney, supra note 87.

129 Anna Levit, et al., Free energy-based reinforcement learning using a quantum processor 5 (2017) (unpublished manuscript), https://arxiv.org/abs/1706.00074.

${ }^{130}$ Id. at 7 .

131 The Grid World Problem is a maze where an agent must choose which path to take to exit the maze. See Jeremy Zhang, Reinforcement Learning - Implement Grid World, TowARDS DATA SCIENCE (May 4, 2019), https://towardsdatascience.com/reinforcement-learning-implement-gridworld-from-scratch-c5963765ebff.

132 Levit, supra note 129 , at 6.

133 "Boltzmann Machines offer a powerful framework for modelling probability distributions. These types of neural networks use an undirected graph structure to encode relevant information." Christa Zoufal, et al., Variational Quantum Boltzmann Machines, 1 (2020) (unpublished manuscript), https://arxiv.org/abs/2006.06004; see also Fabian Ruehle, Data Science Applications to String Theory, PHYSICS REPORTS 90 (2019), https://doi.org/10.1016/j.physrep.2019.09.005 (explaining the DBM is a feed-forward neural network trained with input-out pairs).
} 
Journal of Law, Technology \& the Internet - Vol. 12

\section{IV.PATENTS}

Patents are the most traditional protection for new technologies. ${ }^{134}$ From an informatics perspective, a patent is a document with data about an invention. ${ }^{135}$ Legally, a patent provides the holder a 20-year legal right to prohibit others from using, making, or selling an invention without permission. ${ }^{136}$ In conferring exclusive rights to inventors, a patent grants a de facto monopoly to the holder. ${ }^{137}$ In other words, a patent confers the exclusive rights to use and profit from an invention to the holder, backed by the Government. The United States Patent and Trademark Office ("USPTO") reviews applications to determine whether a claimed invention is: (1) statutory subject matter, ${ }^{138}$ (2) useful, (3) novel, (4) not obvious, and (5) sufficiently described. ${ }^{139}$ Part IV proceeds by surveying patents for claims to QML technologies.

\section{A. MARKET}

Quantum machine learning refers to new technology representing quantum computing and machine learning technical convergence. ${ }^{140}$ This convergence has spawned a new economic market, illustrated by the increasing volume of patents for quantum machine learning technologies. ${ }^{141}$ Quantum machine learning technologies are vital to both the future and present for cybersecurity applications

\footnotetext{
${ }^{134}$ Brian S. Haney, Rocket Patent Strategies, 24 U.S.F. INTELL. Prop. \& TECH. L. J. (forthcoming 2020), https://papers.ssrn.com/sol3/papers.cfm?abstract_id=3437353 [hereinafter "Rocket Patent Strategies"]; see also John PALFREY, INTELL. PROP. STRATEGY 55 (MIT Press 2012).

135 MichaEl BUCKLAND, INFO. AND SOCIETY, 21-23 (2017) (discussing document definitions).

136 "The Congress shall have the Power...To promote the Progress of Science and useful Arts, by securing for limited Times to Authors and Inventors the exclusive Right to their respective Writings and Discoveries." U.S. Const. art. I, § 8, cl. 8; see Stephen Yelderman, The Value of Accuracy in The Patent System, 84 U. CHI. L. REV. 1217, 1270 (2017).

137 Bryce C. Pilz, Student Intellectual Property Issues on the Entrepreneurial Campus, 2 MicH. J. PRIVATE EQUITY \& VENTURE CAP. L. 1, 16 (2012).

${ }^{138}$ The first element of the statutory requirements, statutory subject matter, includes any new process, machine, manufacture, or composition of matter, or any new and useful improvement thereof. 35 U.S.C.S. $§ 101$ (2020).

13935 U.S.C.S. § 112 (2020).

140 "Consistent with this stream of research, we conceive technological convergence as the merging or overlapping of different fields of technology as a result of scientific and technological progress." MARKU, ET AL., supra note 113, at 163.

${ }^{141}$ See Boom in Artificial Intelligence patents, points to 'quantum leap' in tech: UN report, UN NEWS (Jan. 31, 2019), https://news.un.org/en/story/2019/01/1031702.
} 
in modern warfare, ${ }^{142}$ encryption schemes for financial transactions, ${ }^{143}$ and chemical modeling for new drug developments. ${ }^{144}$

\section{DATASET}

To survey patents on subject for this Article, patent data was aggregated from the results of patent claims searches for four terms: "Quantum AND Machine_Learning", "Quantum AND Markov", "Quantum AND Boltzmann", and "Quantum AND Neural_Networks." These search terms were selected to capture instances of quantum reinforcement learning, deep learning, and deep reinforcement learning.

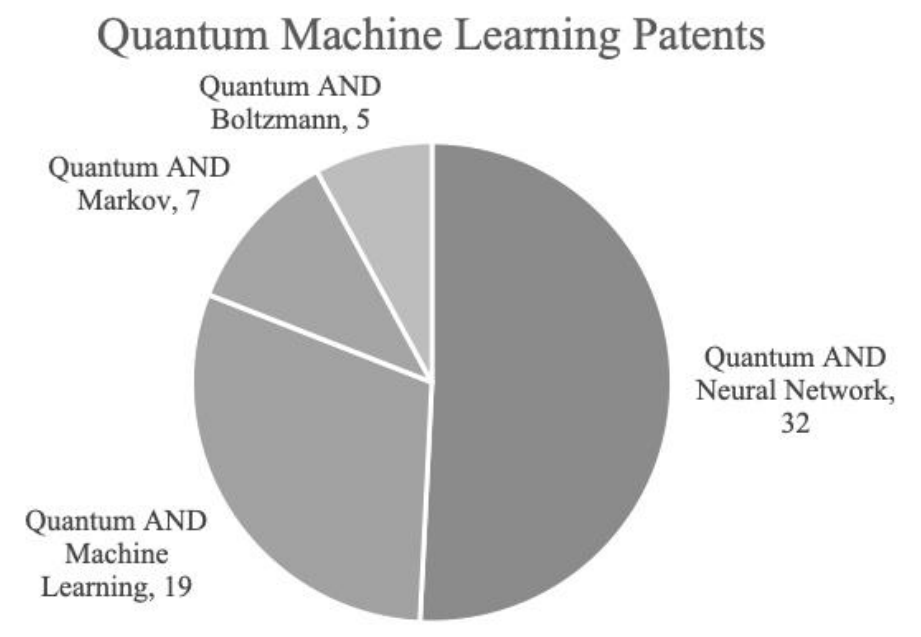

Figure $4^{145}$

The dataset includes 63 total patents, the majority of which relate to neural network technologies. This is unsurprising given the technology's general application across

\footnotetext{
142 See e.g., '553 Patent.

143 Blockchain, supra note 17.

144 See e.g., Tabrez Ebrahim,, Computational Experimentation, 21 VAND. J. OF ENTM'T \& TECH. L. 591 (2019).

145 The information contained in this chart was prepared by the author with information from the United States Patent and Trademark Office. A copy of the data is on file with the author.
} 
industry for predictive purposes. For example, neural networks are used in law for document review ${ }^{146}$ and medicine for diagnostics. ${ }^{147}$

\section{GROWTH TRAJECTORY}

As a whole, the market's trajectory is now experiencing near vertical growth. Interestingly, the market's volumetric increase is more similar to the machine learning patent market than QML patent market. ${ }^{148}$

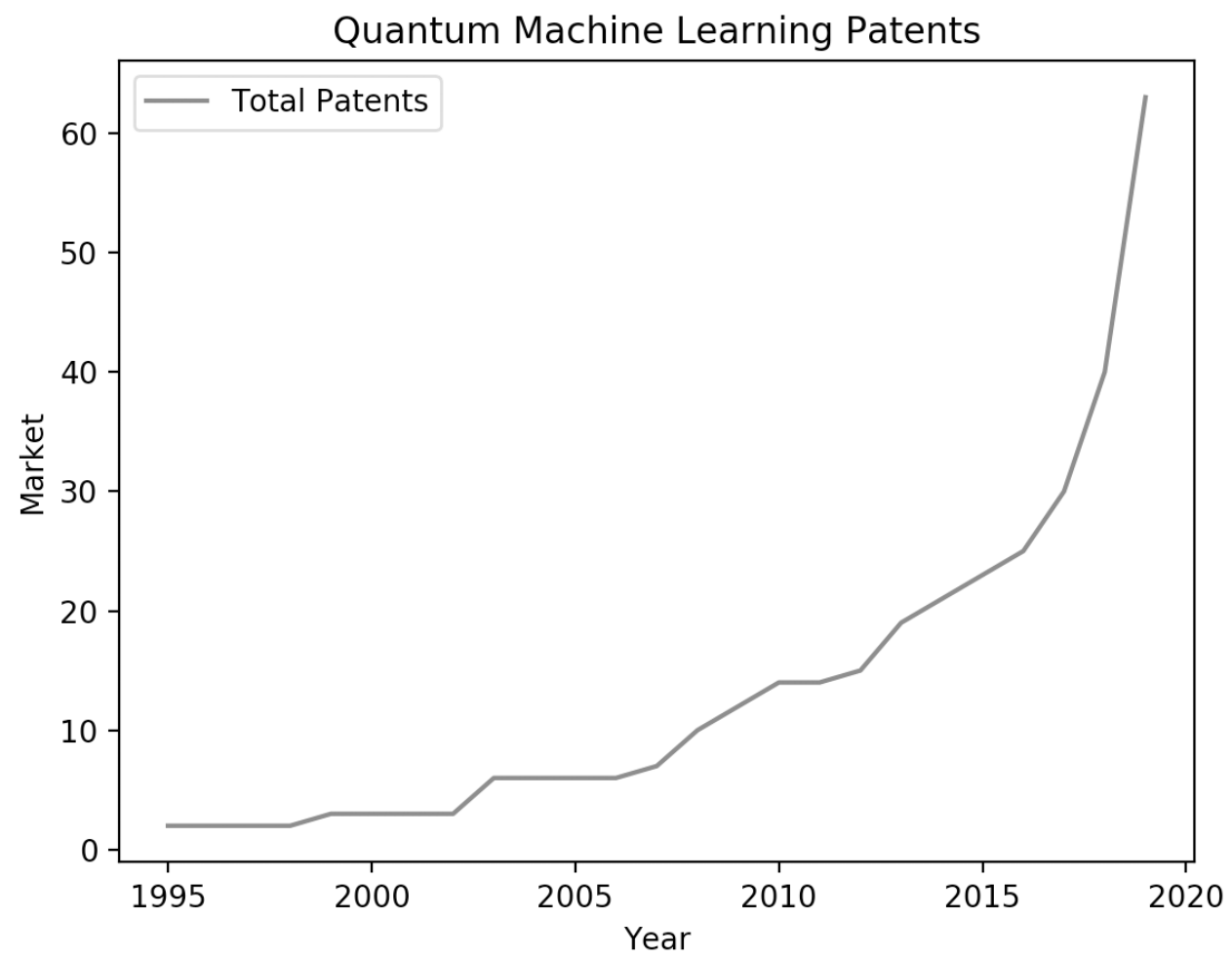

Figure $5^{149}$

In total, this sample reflects a marketplace with sixty-three total patents. By total patents, the market size was 30 in the year 2017, 40 in 2018, and 63 in 2019.

146 See e.g., Applied Natural Language, supra note 63, at 25.

147 See Ava P. Soleimany, et al., Image Segmentation of Liver Stage Malaria Infection with Spatial Uncertainty Sampling (2019) (unpublished manuscript), https://arxiv.org/abs/1912.00262.

148 See Haney, supra note 87.

149 Supra note 145. 


\section{OWNERSHIP}

Figure 6 graphs the firms with the largest stake in the market. These firms reflect the leaders among those developing research at the intersection of quantum computing and machine learning.

\section{QML Patent Ownership}

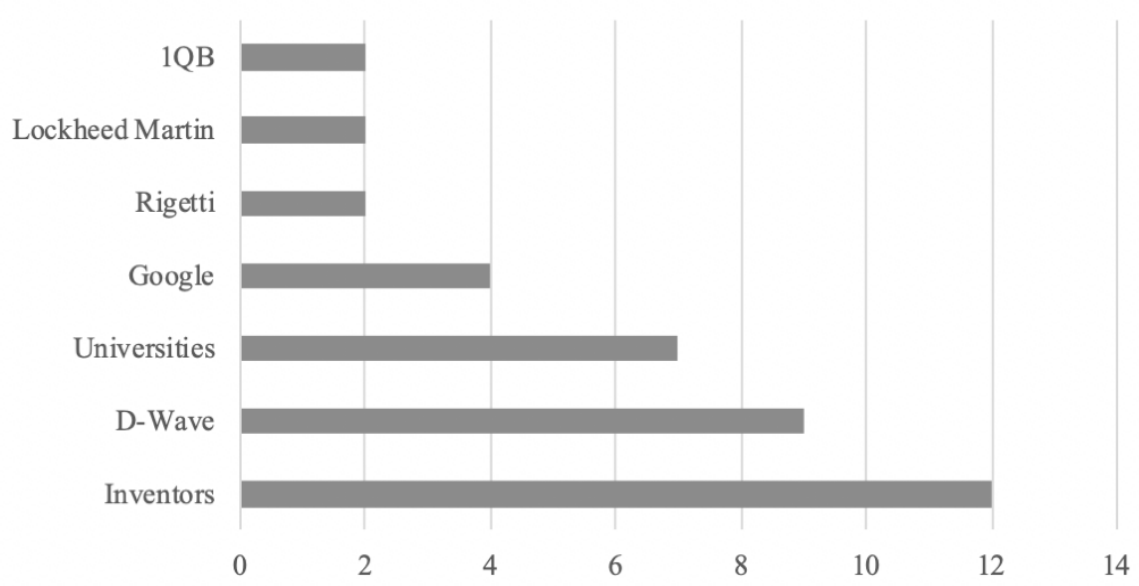

Figure $6^{150}$

Individual inventors own the majority of the market, with 12 total patents belonging to original inventors. D-Wave, the Canadian quantum computing company, is the market's leading firm with nine patents. Universities own seven patents in the dataset. Rigetti, a Y-Combinator startup and full-stack quantum computing company, owns two patents in the sample.

\section{B. Legal Claims}

Patent claims mark the invention's boundaries, defining the particular thing invented and making the public aware of the invention. ${ }^{151}$ Patent claims generally define devices, structures, or methods. ${ }^{152}$ The USPTO will issue a patent only for claims it determines satisfy the statutory requirements, and a challenge to an issued patent will succeed if the challenger can show that any of these requirements have not been met. ${ }^{153}$ Further, courts construe patent claims by starting with the plain

\footnotetext{
${ }^{150} \mathrm{Id}$.

151 Kevin F. O’MAlley, ET AL., 3A Fed. Jury PRAC. \& InSTR. § 158:41 (6th ed. 2019).

152 Mark A. Lemley, The Changing Meaning of Patent Claim Terms, 104 MICH. L. REV. 101, 107 (2005).

153 Max Stul Oppenheimer, Patents 101: Patentable Subject Matter and Separation of Powers, 15 VAND. J. ENT. \& TECH. L. 1, 4 (2012).
} 
meaning, ${ }^{154}$ as they would be understood by a person having ordinary skill in the art. ${ }^{155}$ Claims are the most important part of a patent ${ }^{156}$ because claims are the only part of the patent that can be infringed. ${ }^{157}$

\section{DEFINITENESS}

Patent claims require "definiteness" which demands specifications "shall conclude with one or more claims particularly pointing out and distinctly claiming the subject matter" of the invention. ${ }^{158}$ According to the United States Supreme Court, "a patent is invalid for indefiniteness if its claims, read in light of the specification delineating the patent, and the prosecution history, fail to inform, with reasonable certainty, those skilled in the art about the scope of the invention."159 The reasonable certainty standard balances two interests: ${ }^{160}$ (1) patent claims should provide the public with clear notice of the patent's exclusionary rights; ${ }^{161}$ (2) further, the "definiteness requirement must take into account the inherent limitations of language." 162

There are objective measures for definiteness. ${ }^{163}$ For example, a claim's definiteness depends on whether the terms used in the claim have ascertainable meanings. ${ }^{164}$ Thus, claim term definitions are useful in analysis. ${ }^{165}$ If a particular claim term is not defined in the specification, then this suggests that the claim is less likely to be definite because the patent's specification "may not provide the

${ }^{154}$ See e.g., Gonzales v. Raich, 125 S.Ct. 2195, 2205, 2230 (2005) (Thomas, J., dissenting) (discussing textualism and the plain meaning doctrine).

155 Mark A. Lemley, The Changing Meaning of Patent Claim Terms, 104 MicH. L. REV. 101, 102 (2005).

${ }^{156} \mathrm{Id}$. at 101 .

157 O’MALLEY, ET AL., supra note 151.

15835 U.S.C. $\S 112$ (b) (2012).

159 Nautilus, Inc. v. Biosig Instruments, Inc., 572 U.S. 898, 901 (2014); see also Mark A. Lemley, Software Patents and The Return of Functional Claiming, 2013 WIS. L. REV. 905, 930 (2013) ("A related problem is the uncertainty associated with the meaning and scope of a software patent.").

160 Dean Alderucci, The Automation of Legal Reasoning: Customized AI Techniques for the Patent Field, 58 DUQ. L. REV. 50, 77 (2020).

$161 \mathrm{Id}$. at 77, n.116 ("Clear notice is necessary to avoid '[a] zone of uncertainty which enterprise and experimentation may enter only at the risk of infringement claims."') (internal citations omitted).

162 Nautilus, 572 U.S. at 899.

163 See Alderucci, supra note 160, at 80.

164 Cox Communs., Inc. v. Sprint Comm’n Co. LP, 838 F.3d 1224, 1232 (Fed. Cir. 2016).

165 Alderucci, supra note 160, at 78. 


\section{Quantum Machine Learning: A Patent Review}

person of ordinary skill with enough information to understand the meaning of the term."166

A second example of objective metrics correlating with definiteness is the presence of a coined term. In other words, the patent drafter is permitted to use claim terms of her own devising. ${ }^{167}$ If the term has never appeared in any previous publication, then it is possible that the person of ordinary skill would not ascribe a definite meaning to the term. ${ }^{168}$ Thus, if a claim term is both coined and undefined, the claim is less likely to be considered definite. ${ }^{169}$

Third, descriptive claim terms relating to unspecified limits, terms of degree, ${ }^{170}$ and adjectives ${ }^{171}$ all correlate with a higher probability of indefiniteness. ${ }^{172}$ For example, the claim may include a term of degree, such as a temporal distance between actions that must be "substantially equal." Thus, to avoid indefiniteness there should be some standard for measuring degree. ${ }^{173}$

Consider U.S. Patent 10,396,919, which related to manipulating signals with machine learning. ${ }^{174}$ The terms, artificial neural network, convolutional neural network, and deep dense neural network are all present in the claims. ${ }^{175}$ And yet, none of these terms are defined in the patent. Instead, the patent discusses the terms only by reference, for example, "[t]he machine-learning network may include an artificial neural network (ANN). Adjusting parameters of the machine-learning

166 Id. at 78-79.

167 Id. at 79 ("[T]he patent drafter may invent a new term rather than using a term known in the relevant technical literature. Such terms need not have ever appeared in any previous publication.") (internal citations omitted).

168 Advanced Ground Info. Sys., Inc. v. Life360, Inc., 830 F.3d 1341, 1349-150 (Fed. Cir. 2016) (holding that claim term "symbol generator" was not a term of art and was indefinite).

169 See Capital Sec. Sys. V. NCR Corp., 725 Fed. Appx. 952, 959 (Fed. Cir. 2018) (affirming district court's holding of indefiniteness because the claim term "'transactional operator' has no commonly-accepted definition and its scope is unclear in view of the intrinsic evidence.").

170 See Alderucci, supra note 160, at 80 ("[D] efiniteness does not require . . mathematical precision. Terms of degree without numerical limits can nevertheless be considered definite, particularly if the relevant field of technology admits no more precise way of specifying the invention. The key issue is whether the specification provides some standard for measuring that degree.").

171 Adjectives are problematic because they induce vagueness. For example, adjectives such as "agile" can be ambiguous as to a requisite degree of software agility, thus rendering the term indefinite. $C f$. Halliburton Energy Serv's. v. M-I LLC, 514 F.3d 1244, 1256 (Fed. Cir. 2008) (determining the words "fragile gel" are not sufficiently definite and ambiguous).

172 Alderucci, supra note 160, at 79.

173 See id. at 80.

174 '919 Patent at col. 1, 1. 37-41.

175 Id. at col. 1, 1. 48, 59-60. 
Journal of Law, Technology \& the Internet - Vol. 12

network may include updating at least one of: a connectivity in one or more layers of the ANN, or a weight of connection in one or more layers of the ANN." ${ }^{176}$ And yet, there are many types of artificial neural networks which provide many different ways in which neural architectures may be arranged. ${ }^{177}$ As such, this patent's claims are less likely to be construed as definite if challenged.

In sum, if the claim provides enough certainty to one skilled in the art when read in the invention's context, then the claim is definite. ${ }^{178}$ And, there are at least three objective factors correlating with claim definiteness: "(1) whether the terms in the claims are defined or used in the patent; (2) whether the claim term appears to be coined rather than in common usage; and (3) whether any claim terms are inherently vague words."179

\section{NONOBVIOUSNESS DOCTRINE}

A patent claim is invalid "if the differences between the claimed invention and the prior art are such that the claimed invention as a whole would have been obvious ... to a person having ordinary skill in the art." 180 As NYU Law Professor Jeanne Fromer explains, "The nonobviousness doctrine seeks to ensure that patents are granted only for technologically significant advances to foster the patent system's goal of stimulating useful innovation." 181 In other words, the nonobviousness requirement's goal is to limit patents for only those inventions representing a sufficiently large advance over previously known technology. ${ }^{182}$ The statute requires that obviousness be judged from the perspective of the person having ordinary skill in the art, ${ }^{183}$ and claims be invalidated if that person would find the claimed invention to be obvious. ${ }^{184}$

"A full analysis of the obviousness of a patent claim requires understanding the patent's technology, the state-of-the-art in the technologies field, and the

\footnotetext{
176 Id. at col. 2, 1. 41-45.

177 See Brian S. Haney, Patents for NLP Software: An Empirical Review, IUP J. KNOWLEDGE MGMT. 1, 11 (2020) (defining and discussing recurrent neural network and convolutional neural network architectures).

178 Alderucci, supra note 160 , at 80.

179 Id. at 80-81.

18035 U.S.C. $\S 103$ (2013).

181 Jeanne C. Fromer, The Layers of Obviousness in Patent Law, 22 HARV. J. OF L. \& TECH. 75, 79 (2008).

182 See Sensonics, Inc. v. Aerosonic Corp., 81 F.3d 1566, 1570 (Fed. Cir. 1996).

183 Endress + Hauser Inc. v. Hawk Meas. Sys. Pty., 122 F.3d 1040, 1042 (Fed. Cir. 1997); see also Alderucci, supra note 160, at 70 (analogizing the person having ordinary skill in the art to the "reasonable man" in other areas of law).

184 Alderucci, supra note 160, at 69.
} 


\section{Quantum Machine Learning: A Patent Review}

differences between the two." ${ }^{185}$ For example, consider claim three from U.S. Patent No. 10,229,355 ('355 Patent). ${ }^{186}$

3. A method for training the neural network implemented in the quantum processor claimed in claim 2, the method comprising: providing initialization data for initializing the plurality of couplers and the superconducting quantum circuits of the quantum processor; until a criterion is met: performing a quantum sampling of the quantum processor to provide first empirical means; obtaining at least one training data instance for training the neural network; performing a quantum sampling of the quantum processor; wherein no bias is assigned to the superconducting quantum circuits of the first group: wherein couplings of the first group and the second group are switched off; further wherein the biases of the second group are altered using the biases on a first group of neurons associated with the first group of superconducting quantum circuits, the weights of the switched off couplings, and the at least one training data instance, to determine second empirical means; updating corresponding weights and biases of the couplers and the superconducting quantum circuits of the quantum processor using the first and second empirical means; and providing final weights and biases of the couplers and the superconducting quantum circuits of the quantum processor indicative of data representative a trained neural network. ${ }^{187}$

The '355 Patent's claim three, includes the specific details for a method by which a neural network is implemented on a quantum computer. The state-of-theart in neural network implementations on quantum processors is a complex and convoluted kluge of research, software code, and patents. ${ }^{188}$ As such, implementing a neural network on a quantum processor is obvious. But, by detailing the method

185 Id. at 70 .

186 U.S. Patent No. 10,229,355 col. 1, 1. $24-53$ (issued March 12, 2019).

${ }^{187} I d$.

${ }^{188}$ See Schuld, et al., supra note 51, at 4 ("Reinforcement learning is a central mechanism in the development and study of intelligent agents."); see also '232 Patent at col. 1, 1. 22-28. 
narrowly to the specific application, the claim was granted as a nonobvious improvement. 355' Patent's claim three provides detailed descriptions for the quantum computer's bias, couplings, and the neural network's data flow. ${ }^{189}$

Ultimately, obviousness is a question of law, ${ }^{190}$ but it relies upon factual inquiries including "the scope and content of the prior art, the differences between the prior art and the claims of the patent, and the level of ordinary skill in the art." 191 Further, these factual considerations may be objectively measured to identify probabilistic correlation. The relationship between the prior art and the patent could be objectively measured according to the relative syntactic similarity between the prior art claims and patent claims. ${ }^{192}$ Regardless, a claim's novel is both a critical and complex assessment for QML Patents.

\section{NOVELTY}

A third component for patent claims is that they must claim a novel technology. ${ }^{193}$ Patents represent externally validated technical novelty measured with clear economic significance, such as vetted new products and innovation. ${ }^{194}$ Larissa Bifano, a partner in DLA Piper's Boston Office, and leading expert on machine learning patent explains, "[i]n addition to the technical details, establishing a narrative of the inventive concept can greatly help practitioners during the prosecution stage. ${ }^{" 195}$ Indeed, patent law requires that an invention be novel, or

189 ‘355 Patent at col. 1, 1. 24-53.

190 Graham v. John Deere Co., 383 U.S. 1, 17-18 (1966).

191 Alderucci, supra note 160, at 70 ("Additional facts such as commercial success of the invention, long felt but unsolved needs solved by the invention, and the failure of others to create the invention can also be relevant to determining whether a patent claim is obvious.").

192 Fromer, supra note 181, at 100 ("By demonstrating that obviousness ought to be investigated at an invention's two layers of conception and reduction to practice, this Article provokes a broader question of the relative importance of conception and reduction to practice in the patent system's understanding of invention.”).

193 "The United States Patent and Trademark Office . . . may deny patent applications and trademark registrations to applicants who do not meet the necessary requirements." Sarah Murphy, Heads I Win, Tails You Lose: The "Expense" of a De Novo Review of USPTO Decisions, 60 B.C.L. REV. II.-197, II.-197 (2019); see 35 U.S.C. § 2(a) (2012).

194 M. C. Guardo \& K. R. Harrigan, Shaping the path to inventive activity: the role of past experience in R\&D alliances, 41 J. TECH. TRANSFER 250, 258 (April 2016) ("Not only do they represent an externally validated measure of technological novelty with a clear economic significance, but they have also been empirically shown to correlate very well with other possible measures of technological performance such as new products or innovation counts.").

195 Larissa Bifano, et al., Protecting AI technologies through patents: a US guide, DLA PIPER (May 7, 2020), https://tinyurl.com/4afe5a3k [https://perma.cc/VA3K-ZFME] ("Recent case law and US Patent Office guidance have focused on identifying the technical improvement that results from the artificial intelligence innovation."). 
new. ${ }^{196}$ And yet, still accusations are directed at patent quality, specifically, the lack of novelty in inventions. ${ }^{197}$

Further, the rapid introduction of QML patents into the patent system means that within a relatively short time, the background conditions for QML innovation have been configured. ${ }^{198}$ Consider claim one and three from U.S Patent No. $7,383,235$ ('235 patent): ${ }^{199}$

1. A method for controlling a process driven by a control signal for producing a corresponding output, the method comprising: generating an error signal as a function of a state of the process and of a reference signal; generating a control signal as a function of the error signal and of a parameter adjustment signal and providing the control signal to the process; generating a signal representative of a quantity to be minimized by processing paired values of the state of the process and the control signal; and generating a correction signal from a set of several different values of the control signal that minimizes the generated signal to be minimized, the correction signal being periodically calculated by a Quantum Genetic Search Algorithm comprising a genetic algorithm and a quantum search algorithm merged together...

3. A method according to claim 1 wherein the parameter adjustment signal is generated using a neural network and a fuzzy logic processor based upon the error signal and the correction signal."200

\footnotetext{
196 See e.g., Mark A. Lemley \& Mark P. McKenna, Scope, 57 WM. \& MARY L. REV 2197, 2240 (2016) ("Because patent law requires that an invention be novel and nonobvious, it should be clear that a patent owner is not entitled to sue someone for using technology that existed before she ever 'invented' it.").

197 Stefania Fusco, Trips Non-Discrimination Principle: Are Alice and Bilski Really The End of NPES?, 24 TEX. INTELL. PROP. L.J. 131, 139 (2016).

${ }^{198}$ Cohen, Julie E. and Lemley, Mark A., Patent Scope and Innovation in the Software Industry, 89 CAL. L. REV. 1, 14 (2001).

${ }^{199}$ U.S. Patent No. 7,383,235 (issued June 3, 2008).

${ }^{200}$ Id. at col. 40, 41.
} 
The '235 patent's claims describe integrating a quantum search algorithm with a genetic algorithm, which is then implemented on a quantum processor using a neural network. ${ }^{201}$ Here, the ' 235 patent's drafters advanced the patent's novelty by specifically detailing the innovation. Indeed, quantum search algorithms nor quantum neural networks are novel innovations, but the way in which the patent aggregates these various systems may well be novel. ${ }^{202}$

Further, Professor Elona Marku and Professor Maria Chiara Di Guardo at the University of Cagliari in Italy are developing objective measures for innovation. In fact, they have developed a quality formalism for measuring patent originality, which may be modified to measure novelty. ${ }^{203}$ According to Professor Marku, the algorithmic measure "captures the breadth of the technological knowledge bases that have been synthesized in the focal patent and captures the antecedent technology embodied in each patent." 204 The concept is that the "synthesis of divergent ideas is characteristic of research that is highly original and basic, and that originality stems from the breadth of search." 205

${ }^{201} I d$. at Abstract.

202 See generally, Lov K. Grover, Quantum Computers can Search Arbitrarily Large Databases by a Single Query, 79 PHYSICAL REV. LETTERS 4709 (1997); '466 Patent.

${ }^{203}$ Elona Marku, et al., Quantity at expense of quality? Measuring the effects of "successful" $M \& A$ on innovation performance 8 (2020) (on file with author) [hereinafter "Quantity at the expense of quality?"]. The originality algorithm may be modified as follows to measure novelty:

$$
\text { Novelty }_{i}=1-\sum_{j=1}^{n_{i}} S_{i j}^{2}
$$

where $S_{i j}$ represents the backward citations of patent $i$ that have class code $j$, out of $n_{i}$ different patent technology classes during the four-year, pre-acquisition and post- acquisition windows, respectively.

${ }^{204}$ Quantity at expense of quality?, supra note 203.

${ }^{205}$ M. C. Guardo \& K. R. Harrigan, Shaping the path to inventive activity: the role of past experience in $R \& D$ alliances, $41 \mathrm{~J}$. OF TECH. TRANSFER 250, 259 (2016). 


\section{Quantum Machine Learning: A Patent Review}

\section{SCOPE}

A patent's scope depends on the relevant patent's defined protectable rights. ${ }^{206}$ The scope question is not limited to validity or infringement. ${ }^{207}$ Rather, scope refers to the range of things patent right protects against competition. ${ }^{208} \mathrm{~A}$ patent's scope is largely defined by the claim's transitional phrase. The most common transitional phrases are: comprising, consisting essentially of, and consisting of. ${ }^{209}$ According the United States Patent and Trademark Office: (1) Comprising means the invention includes but is not limited to the elements identified in the claim; (2) Consisting essentially of limits the scope of a claim to the specified materials or steps and those that do not materially affect the basic and novel characteristic(s) of the claimed invention; and (3) Consisting of is closed and means that the invention is limited to the elements identified in the claim. ${ }^{210}$

As such, claim drafting involves a balancing of interest. First, patent rights claiming a broad scope are more likely to be invalid because they may tread on the rights of prior art. ${ }^{211}$ Second, patent rights with a narrower scope are more likely to be valid, but a narrower scope may limit the firm's freedom of action in engineering and design as a result. ${ }^{212}$

The balance of interest in claim drafting is not a dichotomy, but rather a continuous scale, which may be measured with objective metrics. ${ }^{213}$ Appreciation for the balancing of validity and ownership rights is critical for both QML claim drafting. For example, consider the similarities and differences between Google's

\footnotetext{
${ }^{206}$ See Colleen Chien, Software Patents as a Currency, Not Tax, on Innovation, 31 BERKELEY TECH. L.J. 1669, 1681 (2017) ("The boundaries of patent rights are also more readily ascertainable than trade secrets, defining the duration of the right and the scope of the claims so that the parties do not have to do so.").

${ }^{207}$ Mark A. Lemley \& Mark P. McKenna, Scope, 57 WM. \& MARY L. REV 2197, 2202 (2015). IP regimes require, not just similarity between the defendant's and plaintiff's works, but similarity with respect to the protectable elements. Id. at 2209.

${ }^{208}$ See id. (citing Dan L. Burk \& Mark A. Lemley, Policy Levers in Patent Law, 89 VA. L. REV. 1575, 1675 (2003)); see also Stefania Fusco, Trips Non-Discrimination Principle: Are Alice and Bilski Really The End of NPEs? 24 TEX. INTELL. PROP. L.J. 131, 137-138 (2016) (discussing patentable subject matter bounds).

209 Jean Witz \& Kara Geisel, Claim Drafting, U.S. PTO (2017), https://www.uspto.gov/sites/default/files/documents/Website\%20PDF\%20\%20Invention\%20Con\%202017\%20Claim\%20Drafting\%20Workshop\%20-\%20OPLA.pdf.

${ }^{210} \mathrm{Id}$. at 14 .

${ }^{211}$ Lemley \& McKenna, supra note 207.

212 John PALfRey, InTEll. Prop. Strategy 3 (MIT Press, 2012).

213 See Lemley \& McKenna, supra note 207.
} 
Journal of Law, Technology \& the Internet - Vol. 12

'466 patent and Rigetti's '743 patent, both of which claim variant Quantum Boltzmann Machines (QBMs) for machine learning. Google’s ‘466 patent claims:

1. A method performed by a system of one or more computers for probabilistic inference in a model for use in machine learning, the method comprising: receiving data for training the model, the data comprising observed data for training and validating the model, and wherein the model is a modified restricted Boltzmann machine that includes interactions among hidden units of the restricted Boltzmann machine, wherein the interactions are based on hardware connections of a quantum oracle implemented using a quantum machine comprising an adiabatic quantum computing system, the hardware connections comprising couplers that connect qubits included in the quantum oracle; deriving input to the quantum oracle using the received data and a state of the model, the input mapping at least some interactions of different interconnected units of the model to connections between qubits in the quantum oracle; providing the input to the quantum oracle for learning the inference in the model; and receiving from the quantum oracle data representing the learned inference. ${ }^{214}$

The '466 claims a method for probabilistic inference, data processing, and machine learning utilizing a Restricted Boltzmann Machine (RBM) ${ }^{215}$ and a quantum oracle, implemented on and AQC. ${ }^{216}$ The claim narrowly describes the relationship between a quantum oracle, qubit connectivity, and data flow.

Consider the scope of Google's '466 patent's claim 1, compared to the scope of Rigetti's '743 patent's claim 7. Rigetti's '743 patent claims:

\footnotetext{
${ }^{214}$ U.S. Patent No. 10,339,466 (issued July 2, 2019).

${ }^{215}$ See also Geoffrey Hinton, University of Toronto, Advanced Machine Learning: Restricted Boltzmann Machines (2013) (presentation accessed at https://www.cs.toronto.edu/ hinton/csc2535/notes/lec4new.pdf); Volodymyr Mnih, et al., Conditional Restricted Boltzmann Machines for Structured Output Prediction (2012) (unpublished manuscript), https://arxiv.org/abs/1202.3748.

${ }^{216}$ See Adiabatic Quantum Computation with Superconducting Qubits, '283 Patent.
} 
6. The heterogeneous computing method of claim 1 , wherein the computer program code is configured to execute a training algorithm, and the second computing task comprises gradient estimation by quantum sampling.

7. The heterogeneous computing method of claim 6 , comprising: by operation of the host processor unit, obtaining a Boltzmann machine state and a training vector; by operation of the host processor unit, generating the set of instructions for the quantum processor unit based on the Boltzmann machine state and training vector, the set of instructions configured to cause the quantum processor unit to perform a gradient estimation by quantum sampling algorithm based on the Boltzmann machine state and training vector; by operation of the quantum processor unit executing the set of instructions, generating a set of gradient values by executing the set of instructions." 217

The 743 ' patent's claim 7 describes a heterogeneous computing method utilizing gradient estimation, quantum sampling, and a Boltzmann machine state and training vector. ${ }^{218}$ Further, the method's operation as a set of instructions using a quantum processor is claimed. ${ }^{219}$

Some argue the characteristics of the software industry requires a narrow approach to questions of patent scope. ${ }^{220}$ Some contend the process of claim construction determines the patent's scope. ${ }^{221}$ Such an approach is useful in considering the '743 and " 466 patents because literal readings of both patents are subject to narrow interpretation relating to legal claim. While both patents discuss quantum processing methods utilizing a QBM, the claims' structures differ enough to identify their legal and technical independence.

In sum, four important considerations for QML claim drafting are (1) definiteness, (2) non-obviousness, (3) novelty, and (4) scope. Avoiding terms of

${ }^{217}$ U.S. Patent No. 10,402,743, 21 (issued Sep. 3, 2019).

${ }^{218} I d$.

${ }^{219} \mathrm{Id}$.

${ }^{220}$ Cohen \& Lemley, supra note 198 , at 37.

${ }^{221} \mathrm{Id}$. 
degree improves the probability a claim will be interpreted as definite. Obviousness is heavily dependent on a fact intensive analysis, which is highly complex for Quantum Patents. Novelty requires patents represent an externally validated measure of technological significance. Considerations to scope balance the legal claim's breadth and the higher probability narrow patents are ruled valid. Perhaps most importantly, each of these four considerations contribute to the patent's economic value.

\section{Valuation}

In the year 1851, the Economist said, "[p]atents are like lotteries, in which there are a few prizes and a great many blanks." ${ }^{222}$ A report on patent value from 1997 states, "[u]ncertainty about the value of patent is nothing new." ${ }^{223}$ Yet, while some characteristics of the patent market are still analogous to lotteries, others are starkly different. For example, in lotteries, the drawn numbers are random, no one knows which numbers will win prizes and which will be blanks before the drawing, and each ticket has a statistically equal chance to win. But patents are different. With patents, the patents are not filed randomly, one can predict which patents will be valuable and which will be worthless, and one can increase the patent's value proactively - improving the chance a particular patent will be relatively valuable. The key difference is randomness, patents are not randomly valuable.

The way in which patents are valued is a crucial consideration for a firm's strategic planning. The patent system is "designed to encourage innovation by offering a temporary monopoly over inventions or works of authorship." ${ }^{224}$ Yet, one problem with the patent system is that it lacks standard models for valuation. As a result, this author has also argued that patent valuation involves a degree of speculation. ${ }^{225}$ Thus, insights which help to improve patent value objectivity add value to an organization. ${ }^{226}$ In other words, an informed, transparent, and data-

\footnotetext{
${ }^{222}$ Amendment of the Patent Law, THE ECONOMist, Jan. 1, 1851, at 811.

${ }^{223}$ See also Robert Pitkethly, The Value of Patents 1 (J. Inst. Working Paper No. 21) (1997).

${ }^{224}$ Benjamin N. Roin, Intellectual Property Versus Prizes: Reframing the Debate, 81 U. CHI. L. REV. 999, 1001 (2014).

${ }^{225}$ Blockchain, supra note 17, at 149 (presenting a speculation argument as to patent value validity is fallaciously prescriptive because value is inherently subjective rather than intrinsic; indeed, value is a concept ascribed by people to things in their environment, not something intrinsic emanating from objects); see also Pitkethly, supra note 223 at 3 ("Patent valuation requires making judgements about the future in much the same way that stock market prices have embedded in them judgements of investors about the future performance of a company."). ${ }^{226}$ See also Pitkethly, supra note 223 at 19.
} 


\section{Quantum Machine Learning: A Patent Review}

driven decision ${ }^{227}$ within a defined model isn't any more speculative than any other asset valuation. ${ }^{228}$ A review of patent valuation literature reveals three overarching models for patent valuation: income models, cost models, and market models. ${ }^{229}$

\section{MODELS}

Income models value assets based on the economic benefit expected to be received over the asset's life. ${ }^{230}$ The underlying theory is that the extent to which patents affect a technologies ability to generate income, influences the patents valuation. ${ }^{231}$ Factors for income models include: future profits, reasonable royalty, and cash flow analysis. ${ }^{232}$ Income models are particularly popular for determining damages in patent litigation, which can help to determining patent value. ${ }^{233}$ But, income models struggle to account for investment costs, which mature over time and are subject to market uncertainties.

"[C]ost models . . a are based on the idea that the trade secret is worth the amount it cost its owner to develop and protect." 234 The assumption underlying cost models is the expense of developing a new asset is commensurate with the economic value the asset can provide during its life. ${ }^{235}$ Cost models are favorable to QML technology - which has most of its value in the future. Cost models incentivize firms to keep good accounts of research and development (R\&D) spending, making the model appealing for its precision. ${ }^{236}$ But, it is likely some QML R\&D cost and financial information is classified due to the technology's

\footnotetext{
${ }^{227}$ Note that most daily decisions are made unconsciously. See Andrew Campbell et al., Why Good Leaders Make Bad Decisions, HARV. BUS. REV. (February 2009).

${ }^{228}$ JAMES W. CORTADA, INFO. AND THE MODERN CORP. 3-4 (2011) (discussing knowledge as a vital asset class for corporations).

${ }^{229}$ Rocket Patent Strategies, supra note 134, at 9.

${ }^{230}$ See Ted Hagelin, A New Method to Value Intellectual Property, 30 AIPLA Q.J. 353, 363 (2002) (discounting on the asset's present value).

${ }^{231}$ See id. at 364.

${ }^{232}$ See generally Gavin C. Reid et al., What's it Worth to Keep a Secret?, 13 DuKE L. \& TECH. REV. 116 (2015).

${ }^{233}$ Amy L. Landers, Patent Valuation Theory and the Economics of Improvement, 88 TEX. L. REV. 163, 166 (2010) ("Patent damages are a make-whole remedy, intended to restore the patentee to the same position as before the infringement."); see also Mark A. Lemley, Distinguishing Lost Profits from Reasonable Royalties, 51 WM. \& MARY L. REV. 655, 669 (2009) (explaining that patent law aims to provide patentees with payment for lost profits and other competitive harm suffered through infringement).

${ }^{234}$ Reid, et al., supra note 232, at 139.

235 See Hagelin, supra note 230, at 359.

${ }^{236} \mathrm{Id}$. at 360.
} 


\section{Journal of Law, Technology \& the Internet - Vol. 12}

potential for cybersecurity ${ }^{237}$ and defense applications. ${ }^{238}$ Regardless for QML technology, costs models may raise $\mathrm{R} \& \mathrm{D}$ costs, patent prosecution fees, ${ }^{239}$ and engineering fees. ${ }^{240}$

Market models define fair market value for a technology. ${ }^{241}$ The global quantum computing market's value remains difficult to define, but recent reports suggest in the aggregate the market is receiving at least $\$ 8$ billion in both public and private investment annually. ${ }^{242}$ The fair market value for a particular patent in the market is determined by assessing the price a buyer would pay a seller for the technology. ${ }^{243}$ In addition to a technology's market value, the technology's commercialization is also important in this assessment. ${ }^{244}$ A patent's ability to sells

${ }^{237}$ In the aggregate, "U.S. payment, clearing, and settlement systems process approximately 600 million transactions per day, valued at over $\$ 12.6$ trillion. Many of these systems rely on security systems rely Public-Private Key Cryptography." Blockchain, supra note 17, at 126. And, according to a Royal Society Open Science Report, quantum computers are "capable of deducing the private key from a formerly revealed public key with little effort." I. Stewart, et al., Committing to Quantum Resistance: A Slow Defense for Bitcoin Against a Fast Quantum Computing Attack., R. SoC. OPEN SCI. 5: 180410, at 5 (2018), https://royalsocietypublishing.org/doi/10.1098/rsos.180410.

${ }^{238}$ See Brian S. Haney, Automated Source Selection \& FAR Compliance, 48 PUB. CONT. L.J. 751 (2019) (stating that the United States annual defense budget exceeds $\$ 700$ billion).

${ }^{239}$ Stuart J.H. Graham \& Ted Sichelman, Why Do Start-Ups Patent? 23 BERKELEY TECH. L.J. 1063, 1085 (2008) ("Simple economics suggest that the high cost of patenting will deter some inventors from filing.").

${ }^{240}$ One factor which may be considered in a cost model is a patent's inventorship. It follows, the inventor's prestige and time spent developing a patent may be considered correlational with patent quality. "However, a counterargument is such estimations may overlook inventions by a single previously unknown inventor which took substantial time and effort." Heather Hamel, Valuing the Intangible: Mission Impossible? An Analysis of The Intellectual Property Valuation Process, 5 CYBARIS 183, 187 (2014). Prestige and time may also correlate with the capacity of a granted patent to meet "the statutory standards of patentability - most importantly, to be novel, nonobvious, and clearly and sufficiently described." R. Polk Wagner, Understanding PatentQuality, 157 U. PA. L. REV. 2135, 2138-39 (2009).

${ }^{241}$ See Gavin C. Reid, et al., What's it Worth to Keep a Secret?, 13 DuKE L. \& TeCH. REV. 116, 140 (2015).

${ }^{242}$ See QuANTUM COMPUTING: PROGReSS AND PROSPECTS, 7-18 (Emily Grumbling \& Mark Horowitz eds., The National Academies Press 2018) (defining investments by China, the UK, Australia, Sweden, and the EU).

The broader technology market accounts for more than $\$ 12$ trillion in annual economic activity. See also HuAWEI \& OXFORD ECONOMICS, DigitAl SPILlOVER, MEASURING THE TRUE IMPACT OF THE Digital ECONOMY 2, 29 (2017) (measuring market in 2016 as \$11.5 trillion, growing at 2.5x the rate of global GDP); JoHN PALFREY, INTELLECTUAL PROPERTY STRATEGY 126 (MIT Press 2012).

${ }^{243}$ See Hamel, supra note 240, at 204.

${ }^{244}$ See W. Michael Shuster, Artificial Intelligence and Patent Ownership, 75 WASH. \& LEE L. REV. 1945, 1985 (2018). 


\section{Quantum Machine Learning: A Patent Review}

impacts its market valuation. ${ }^{245}$ For example, ownership rights in the latest QML technologies for cybersecurity or supply chain optimization increase firm value insofar as the underlying technology can be sold or licensed. ${ }^{246}$

Yet still, no single formalized rule exists for technology valuation. ${ }^{247}$ The aim in valuing patents is to enable those managing them to know their value sufficiently accurately to make well-founded decisions concerning their management. ${ }^{248}$ Therefore, there exists a need for formalized and objective patent value metrics to improve efficiency, objectivity, and transparency in technology transactions.

\section{METRICS}

Some view "patents as economic assets, per se."249 Yet, many patents turn out to be worthless. ${ }^{250}$ Others argue, "any valuation method is merely a starting point or a help towards better decision making." ${ }^{251}$ By defining objective patent value metrics with reference to the three valuation models, this Article aims to provide a concrete framework for QML Patent valuation. One scholar argues valuable patents can be identified, at least in the aggregate. ${ }^{252}$ Substantively, valuable patents cite more prior art, make more claims, and have more inventors. ${ }^{253}$

\footnotetext{
${ }^{245}$ See Malcom T. Meeks \& Charles A. Eldering, PhD, Patent Valuation: Aren't We Forgetting Something? Making the Case for Claims Analysis in Patent Valuation by Proposing a Patent Valuation Method and a Patent-Specific Discount Rating Using the CAPM, 9 Nw. J. TECH. \& INTELL. PROP. 194, 199 (2010); see also Shuster, supra note 244, at 1987 ("“A]ny patentee can attempt to monetize its patents by selling the rights to practice the technology[.]"). ${ }^{246}$ Shuster, supra note 244, at 1987.

${ }^{247}$ Landers, supra note 233, at 165.

${ }^{248}$ See Pitkethly, supra note 223, at 5 (For example, "to decide how much to pay for or invest in a business as part of the firms overall financial planning.").

${ }^{249}$ Meeks \& Eldering, supra note 245, at 194 (emphasis added).

${ }^{250}$ John R. Allison et al., Valuable Patents, 92 GEO. L.J. 435, 437 (2004) (“[E]ither because the inventions they cover turn out to be worthless, or because even if the invention has economic value the patent does not.").

${ }^{251}$ Pitkethly, supra note 223, at 8 .

${ }^{252}$ See Allison, et al., supra note 250, at 438 (arguing data empirically demonstrates that "valuable patents differ in substantial ways from ordinary patents both at the time the applications are filed and during their prosecution.").

${ }^{253}$ See id. at 438 (Allison argues six "key characteristics of litigated patents are: (1) They tend to be young-litigated soon after they are obtained. (2) They tend to be owned by domestic rather than foreign firms. (3) They tend to be issued to inventors or small companies, not to large companies. (4) They cite more prior art than non-litigated patents, and in turn are more likely to be cited by others. (5) They spend longer in prosecution than ordinary patents. (6) They contain more claims than ordinary patents."); see also Hamel, supra note 240, at 187 (stating that a common
} 
Allison's work provides strong support for general correlations between valuable and non-valuable patents. ${ }^{254}$ Consider figure 7, which graphs QML patents by two metrics correlating with patent value:

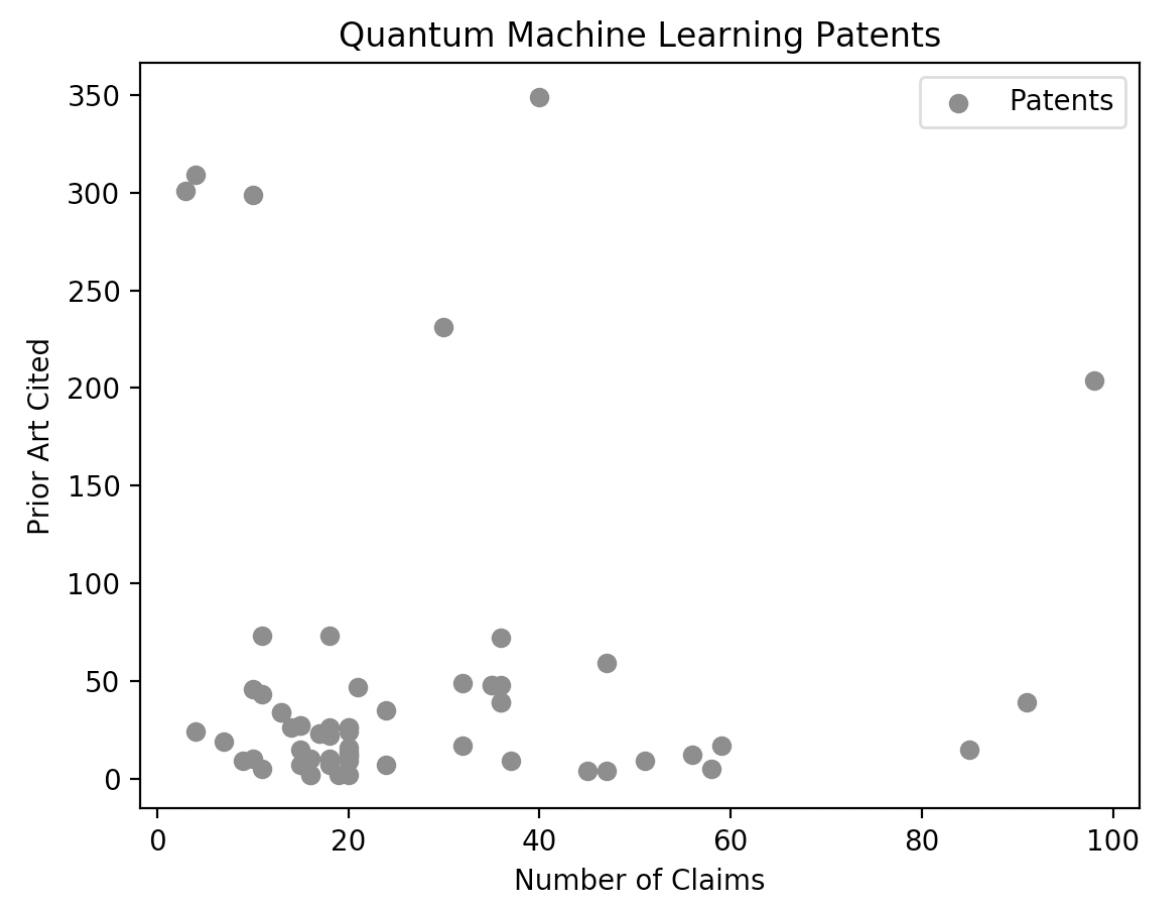

Figure $7^{255}$

Figure 7 graphs QML patents by prior art cited and the number of claims. According to one theory, ${ }^{256}$ patents plotted toward the graph's upper right corner will tend to be more valuable.

One problem that exists is how to use this information to more effectively make patent strategy decisions. One solution is to use factors correlating with patent value, an expert system may be developed to formalize the decision-making process altogether. In other words, the expert system can assign a dollar value to any patent

argument is the greater the number and prestige of the inventors on a patent, the higher the patent quality because more intelligence and time was dedicated to the patent); R. Polk Wagner,

Understanding Patent-Quality, 157 U. PA. L. REV. 2135, 2138 (2009) (prestige and time may also correlate with the capacity of a granted patent to meet "the statutory standards of patentability most importantly, to be novel, nonobvious, and clearly and sufficiently described.").

${ }^{254}$ See Allison, et al., supra note 250, at 438.

255 Supra note 145.

${ }^{256}$ See Allison, et al., supra note 250, at 438 (showing that patents that cite more prior art and have more claims are more valuable). 


\section{Quantum Machine Learning: A Patent Review}

or group of patents. Two ways in which an expert system may be developed are with a weighted geometric valuation and a V-score valuation. First, one method of formalizing human intuition in decision making is a weighted geometric mean. ${ }^{257}$ While patent valuation is inherently subjective, the weighted geometric mean provides a method to more objectively measure patent value, by flexibly combining a variety of objective metrics. ${ }^{258} \mathrm{~A}$ second method is to apply a V-Score patent valuation algorithm to dataset. ${ }^{259} \mathrm{~V}$-scores may be particularly efficacious in forecasting the content of firms' organizational learning because of how they characterize changes in firms' technology trajectories. ${ }^{260}$ As such, the utility gained from either algorithm is a standardized method for proactive QML patent value optimization. Firms and inventors can optimize the algorithm's metrics while writing a patent and in turn optimize their patent value. Further, one new method for patent valuation evolving in research is options pricing.

${ }^{257}$ See Ron Dolin, Measuring Legal Quality: Purposes, Principles, Properties, Procedures, and Problems (June 18, 2017) (unpublished manuscript) (on file with Harvard Law School), https://papers.ssrn.com/sol3/papers.cfm?abstract_id=2988647. Formally the weighted geometric mean is described:

$$
s=\sqrt[\sum_{i=1}^{n} w_{j}]{\prod_{i}^{n} F_{i}}
$$

In the above equation $s$ is the document score; $n$ represents the number of factors $F_{i}$; and $W_{i}$, is the per factor weight. The square root is a summation equation designed to calculate the total weight for all factors.

${ }^{258} I d$. at 4, 6.

${ }^{259}$ Kathryn Rudie Harrigan, et al., Using a distance measure to operationalize patent originality (2016), https://doi.org/10.1080/09537325.2016.1260106.

$$
V=\left[\left[\sum_{k=1}^{n_{i}} f_{i}\right]+\left[\sum_{k=1}^{m_{o}} f_{0}\right] \times\left[\left[\sum_{j=1}^{n_{i}} p_{i j} / i_{n}\right]+\left[\sum_{j=1}^{m_{o}} p_{o j} / o_{m}\right]\right] \times\left[\sum_{o=1}^{m} f_{o} / \sum_{i=1}^{n} f_{i}\right]\right]
$$

${ }^{260}$ See Kathryn Rudie Harrigan, et al., Using a distance measure to operationalize patent originality (2016), https://doi.org/10.1080/09537325.2016.1260106; see also Kathryn Rudie Harrigan, et al., Patent value and the Tobin's q ratio in media services, $43 \mathrm{~J}$. TECH. TRANSFER 24 (2018). 


\section{OPTIONS}

Substantive economics scholarship exists analogizing patents to real options. ${ }^{261}$ Real options are a financial derivatives contract ${ }^{262}$ which create the right, not the obligation, to purchase an underlying asset at a defined price. ${ }^{263}$ Real options theory is used in strategic resource allocation to value flexibility. ${ }^{264}$ Essentially, the real options approach seeks to formalize intangible asset valuation. ${ }^{265}$ For example a firm can use options to define the value of an ability to close and then reopen a natural resource mine. ${ }^{266}$

Every option has a price and the decisions available to a company can be characterized as real options and defined in terms of value by elements like exercise price or expiration date. ${ }^{267}$ There are five key elements for options: (1) a right but not an obligation, (2) at or before some specified time (3) to purchase - a call option, or sell - a put option (4) at a prespecified price - the exercise price (5) an underlying asset whose price is subject to some form of random variation. ${ }^{268}$

One theory is that "[a] patent is like a real option[] . . because it allows the owner to choose between exclusively commercializing the patented invention ... or foregoing commercialization altogether." ${ }^{269}$ As a consequence, recent attempts in patent valuation efforts have been developed within the real options theory,

${ }^{261}$ Christopher A. Cotropia, Describing Patents as Real Options, 34 J. CORP. L. 1127, 1128 (2009).

${ }^{262}$ Nikitas Stamatopoulos et al., Option Pricing using Quantum Computers, 4 QUANTUM 291 (2017), https://arxiv.org/abs/1905.02666 (“Options are financial derivative contracts that give the buyer the right, but not the obligation, to buy (call option) or sell (put option) an underlying asset at an agreed-upon price (strike) and timeframe.").

${ }^{263}$ Cotropia, supra note 261, at 1128; see also Andrew Chin, Teaching Patents as Real Options, 95 N.C. L. REV. 1433, 1441 (2017) ("A real option is the right, but not the obligation, to pay a predetermined price to undertake a potentially profitable action in the future.").

${ }^{264}$ See Cotropia, supra note 261, at 1131.

${ }^{265} I d$.

${ }^{266} I d$.

${ }^{267} I d$.

${ }^{268}$ Dr. R. Pitkethly, Said Business School at University of Oxford, Valuation of Patents (presentation available at http://www.unece.org/fileadmin/DAM/ie/enterp/documents/k.pdf) [hereinafter "Valuation of Patents"]; see also Robert Pitkethly, THE VALUATION OF PATENTS 10 (1997), http://users.ox.ac.uk/ mast0140/EJWP0599.pdf; Chin, supra note 263, at 1441 ("Real options also follow the terminology of financial options in distinguishing between European and American types. A European option can be exercised only on the expiration date, while an American option can be exercised at any time up to and including the expiration date."). ${ }^{269}$ Cotropia, supra note 261, at 1128. 


\section{Quantum Machine Learning: A Patent Review}

which recognizes the effect of uncertainty on patent value. ${ }^{270}$ In fact, economists use real options analysis to place specific values on patents. ${ }^{271}$ The option's importance in patent valuation is more critical early in the patent's life. ${ }^{272}$

One of the first steps in framing patents as real options is to define the patent's purchase price. ${ }^{273}$ For example, the patent's filing fee constitutes one component of the patent option price. ${ }^{274}$ Additionally, drafting fees may also be included in the options price. ${ }^{275}$ The option price also includes the cost of creating the invention. ${ }^{276}$ Further, the patentability requirements define this aspect of the option price. ${ }^{277}$ For QML patents, options pricing may be valuable reflecting the need for narrow and specialized skillsets in drafting. ${ }^{278}$

In particular, the licensing contract is analogous to a financial call option. ${ }^{279}$ A call option provides its owner with the right but not the obligation to buy an underlying financial asset at a predetermined exercise price before a given maturity date. ${ }^{280}$ Thus, licensing contracts provide the licensee with the opportunity to acquire the cash flows from the commercialization of the patented technology. ${ }^{281}$ For example, when entering a licensing contract for QML technology, the licensee may pay an initial fee to acquire the right to develop and commercialize the underlying technology. ${ }^{282}$ As such, some argue that research and development funding is the same as purchasing a call option on the resulting technology. ${ }^{283}$

Most research focuses on the Black-Scholes-Merton model for options pricing. ${ }^{284}$ The Black-Scholes-Merton model is based on simplifying assumptions about the statistical movement of stock prices and market efficiency ${ }^{285}$ First, all

\footnotetext{
${ }^{270}$ Maria Isabella Leone \& Raffaele Oriani, The Option VALUE OF PATENT Licenses 2 (2007), https://www.researchgate.net/publication/252398618_The_option_value_of_patent_licenses.

${ }^{271}$ Cotropia, supra note 261, at 1128.

${ }^{272}$ See Valuation of Patents, supra note 268.

${ }^{273}$ Cotropia, supra note 261, at 1135.

${ }^{274} \mathrm{Id}$.

${ }^{275} \mathrm{Id}$.

${ }^{276} I d$.

${ }^{277} I d$.

${ }^{278}$ See id.

${ }^{279}$ Leone \& Oriani, supra note 270 , at 5.

${ }^{280} \mathrm{Id}$.

${ }^{281} I d$. (stating the net present value for a patent license is subject to volatility stemming from different sources of uncertainty).

282 Id.

283 Cotropia, supra note 261, at 1132.

${ }^{284}$ See Chin, supra note 263, at 1443.

${ }^{285} \mathrm{Id}$. at 1444.
} 
investors in the options market have sufficient liquidity to conduct certain hedging strategies. ${ }^{286}$ Second, the market must have sufficient efficiency and liquidity allowing investors to complete necessary trades. ${ }^{287}$ Third, the underlying stock's price movement has statistical properties associated with geometric Brownian motion. ${ }^{288}$ Perhaps it's curious similar random rules most rigorously describe economic markets, computers, and the physical Universe. ${ }^{289}$

\section{V.FUTURE}

In a world where most people think technology is a fast-paced game, ${ }^{290}$ progress has never been slower. Consider the ideas behind quantum computers were conceived in the year 1942. ${ }^{291}$ The technologies mature evolution is likely decades away. But this makes the QML patents awarded to firms today all the more important. Indeed, government contracts for research and development are often awarded to firms with the financial resources to obtain patents. ${ }^{292}$ These contracts often evolve over time providing substantial competitive advantages to firms with more patents. ${ }^{293}$ As such, the number of QML patents is expected to accelerate like the machine learning patent market is evolving. ${ }^{294}$ Increases in federal funding should further accelerate QML technical advancement. ${ }^{295}$

\footnotetext{
${ }^{286} \mathrm{Id}$.

${ }^{287} \mathrm{Id}$.

${ }^{288} I d$.

${ }^{289}$ MARGARET CuONZO, PARADOX 206 (2014) ("Should we consider quantum mechanics a progressive or degenerating research program?").

${ }^{290}$ Conventional wisdom teaches technological progress is driven by the Law of Accelerating Returns (LOAR). The LOAR's application to information technology, Moore's Law, projects exponential trends in technological progress toward an ultimate technological singularity. ${ }^{291}$ R.P. Feynman, The Principle of Least Action in Quantum Mechanics 1, 3 (May 1942) (unpublished Ph.D. dissertation, Princeton University) (on file with the CERN Library Document Server) ("Plank's discovery in 1900 of the quantum properties of light led to an enormously deeper understanding of the attributes and behaviour of matter, through the advent of the methods of quantum mechanics .... The fundamental ... phenomena in nature are symmetrical with respect to interchange of past and future.").

292 Rocket Patent Strategies, supra note 134, at 9.

${ }^{293}$ Id.

294 See AI Patents, supra note 56.

295 Exec. Order No. 13,885, 84 Fed. Reg. 46,873 (Aug. 30, 2019).
} 
Quantum Machine Learning: A Patent Review

APPENDIX 
Journal of Law, Technology \& the Internet - Vol. 12

APPENDiX A. NOTATION SUMMARY

\begin{tabular}{|c|c|}
\hline Notation & Meaning \\
\hline$H_{S}(s)$ & The energy of a system. \\
\hline$-\frac{1}{2} \sum_{i} \Delta(s) \sigma_{i}^{x}$ & The Initial Hamiltonian. \\
\hline & The Final Hamiltonian. \\
\hline$\sigma^{Z}$ & Pauli matrices. \\
\hline$I$ & Identity transformation. \\
\hline$X$ & Negation. \\
\hline$\otimes$ & Tensor product. \\
\hline$|x\rangle\langle y|$ & The outer product of $|x\rangle$ and $\langle y|$. \\
\hline $\mathbb{E}[x]$ & Expectation of random variable. \\
\hline $\arg \max _{a} f(a)$ & $\begin{array}{l}\text { A value of } a \text {, at which } f(a) \text { takes its } \\
\text { maximal value. }\end{array}$ \\
\hline$r$ & Reward. \\
\hline$\pi^{*}$ & Optimal policy. \\
\hline $\mathrm{Q}(s, a)$ & Q-function. \\
\hline$(s, a)$ & State-action pair. \\
\hline$\phi$ & Q-function parameters. \\
\hline$\gamma$ & Discount factor. \\
\hline$\pi^{*}$ & Optimal policy. \\
\hline
\end{tabular}


Appendix B. Top Ten Most Valuable QML Patents

\begin{tabular}{|c|c|c|c|c|}
\hline Rank & $\begin{array}{l}\text { U.S. } \quad \text { Patent } \\
\text { No. }\end{array}$ & Title & Owner & Year \\
\hline 1 & $10,417,553$ & $\begin{array}{l}\text { Quantum-assisted training of } \\
\text { neural networks }\end{array}$ & $\begin{array}{l}\text { Lockheed } \\
\text { Martin }\end{array}$ & 2019 \\
\hline 2 & $10,229,355$ & $\begin{array}{l}\text { Quantum processor and its use } \\
\text { for implementing a neural } \\
\text { network }\end{array}$ & $\begin{array}{l}\text { 1QB } \\
\text { Information } \\
\text { Technologies } \\
\text { Inc. }\end{array}$ & 2019 \\
\hline 3 & $10,402,743$ & $\begin{array}{l}\text { Operating a quantum processor } \\
\text { in a heterogeneous computing } \\
\text { architecture }\end{array}$ & Rigetti & 2019 \\
\hline 4 & $10,339,466$ & $\begin{array}{l}\text { Probabilistic inference in } \\
\text { machine learning using a } \\
\text { quantum oracle }\end{array}$ & Google & 2019 \\
\hline 5 & $10,396,919$ & $\begin{array}{l}\text { Processing of communications } \\
\text { signals using machine learning }\end{array}$ & $\begin{array}{l}\text { Virginia } \\
\text { Tech } \\
\text { Intellectual } \\
\text { Properties, } \\
\text { Inc. }\end{array}$ & 2019 \\
\hline 6 & $10,068,183$ & $\begin{array}{ll}\text { Bioinformatics } & \text { systems, } \\
\text { apparatuses, and } & \text { methods } \\
\text { executed on a } & \text { quantum } \\
\text { processing platform } & \\
\end{array}$ & $\begin{array}{l}\text { Edico } \\
\text { Genome, } \\
\text { Corp. }\end{array}$ & 2018 \\
\hline 7 & $9,130,651$ & $\begin{array}{l}\text { Mega communication and } \\
\text { media apparatus configured to } \\
\text { provide faster data } \\
\text { transmission speed and to } \\
\text { generate electrical energy }\end{array}$ & Joseph Tabe & 2016 \\
\hline 8 & $8,606,526$ & $\begin{array}{l}\text { Pharmaco-genomic mutation } \\
\text { labeling }\end{array}$ & $\begin{array}{l}\text { Dennis } \\
\text { Fernandez } \\
\text { and Antonia } \\
\text { Maninang }\end{array}$ & 2013 \\
\hline 9 & $7,469,237$ & $\begin{array}{l}\text { Method and apparatus for } \\
\text { fractal computation }\end{array}$ & $\begin{array}{l}\text { David L. } \\
\text { Cooper }\end{array}$ & 2008 \\
\hline
\end{tabular}


Journal of Law, Technology \& the Internet - Vol. 12

\begin{tabular}{|l|l|l|l|l|}
\hline & & & & \\
\hline 10 & $10,469,087$ & $\begin{array}{l}\text { Bayesian tuning for quantum } \\
\text { logic gates }\end{array}$ & Microsoft & 2019 \\
\hline
\end{tabular}

